Portland State University

PDXScholar

$1-1-2011$

\title{
Sustainable Event Management of Music Festivals: An Event Organizer Perspective
}

Stephanie L. Stettler

Portland State University

Follow this and additional works at: https://pdxscholar.library.pdx.edu/open_access_etds

Part of the Educational Leadership Commons

Let us know how access to this document benefits you.

\section{Recommended Citation}

Stettler, Stephanie L., "Sustainable Event Management of Music Festivals: An Event Organizer Perspective" (2011). Dissertations and Theses. Paper 257.

https://doi.org/10.15760/etd.257

This Thesis is brought to you for free and open access. It has been accepted for inclusion in Dissertations and Theses by an authorized administrator of PDXScholar. Please contact us if we can make this document more accessible: pdxscholar@pdx.edu. 
Sustainable Event Management of Music Festivals:

An Event Organizer Perspective

by

Stephanie L. Stettler

A thesis submitted in partial fulfillment of the requirements for the degree of

Master of Science

in

Education: Policy, Foundation and Administration

Thesis Committee:

Heather Burns, Chair

Andy Job

Mary C. King

Portland State University

(C) 2011 


\begin{abstract}
Sustainably managed music festivals have significant value and can provide a multitude of benefits to a healthy, sustainable and desirable society if their negative impacts are mitigated and positive impacts cultivated. To reach this great potential, sustainable event management of music festivals must become widely adopted and expanded as common practice. To drive this improvement of sustainable event management, there is a need to first understand the barriers and success factors event organizers face moving their music festivals toward sustainability. This study uses a research design of mixed quantitative-qualitative methods: a survey of thirty diverse music festival organizers across the United States and interviews with five selected survey participants. Research draws on pertinent literature from sustainability theory and practice, previous research on sustainable event management, existing strategies of sustainable events, and lessons from organizational change studies. Findings revealed seven key barriers and four success factors associated with sustainable event management of music festivals as well as three specific needs of event organizers to improve sustainable event management. With these findings, seven strategies are presented to help event organizers adopt and improve sustainable event management of music festivals. This study is significant because it fills an important gap in the academic literature on events and sustainability. Additionally, this study is immediately applicable to Untied States music festivals. The findings were drawn directly from the perspectives and experiences of event organizers, and the strategies are designed to be specifically applied to their sustainable event management work.
\end{abstract}




\section{Acknowledgments}

Through the course of the past year and through all the moments of stress and frustration that were a part of this process, I looked forward to writing this page. The opportunity to write this acknowledgements page and give thanks is my reward for completing this challenging and fulfilling project. I'm very grateful for all of those who helped me accomplish this feat. I couldn't have done it without them.

My mom gave me the pep talks I needed and always managed to convince me that I could do it. My sister sat on the other side of the phone at all hours listening to me rattle on about my metal blocks. My dad's unwavering pride in me motivated me to continue pushing forward. My family is my constant, as they have always been.

My advisor, Heather, has been amazing. She helped me develop every step of this project. Most importantly, her skillful guidance as a sustainability education practitioner is the reason why my experience in the LSE program has been a whole sustainability journey rather than a conventional two-year master's program.

My beautiful LSE cohort is loving, supportive, and courageously passionate. I'm grateful to have taken this transformational journey through LSE with them. The PSU sustainability community is full of energy and gave me opportunities to turn my ideas into reality. PSU really is blossoming into a fruitful living laboratory, and I'm grateful to have participated in its budding stages.

My Grandma and Grampa have believed in me my entire life and given me more love than a person knows what to do with. I wouldn't have had the opportunity to write this thesis without their generosity to support me in my graduate education. They have been a constant joy in my life, and have helped to create the person I am today. 
Lastly, thank you to the music. The music always reminded me why I had embarked on this journey. It is an endless source of inspiration and motivation. 
Table of Contents

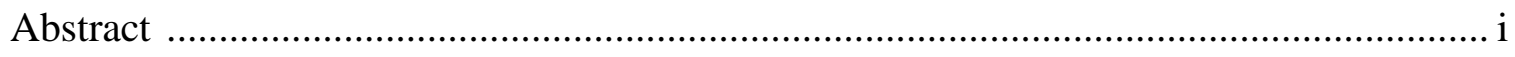

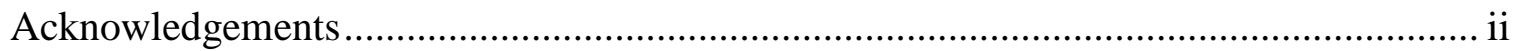

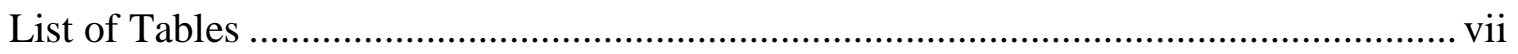

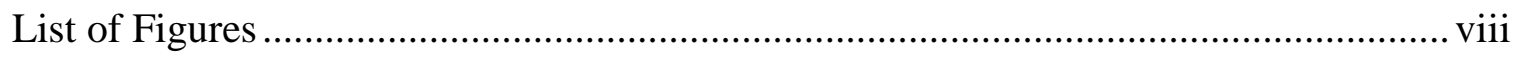

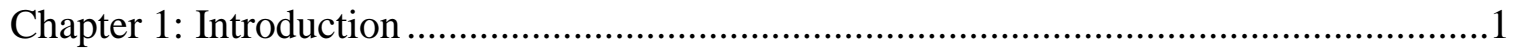

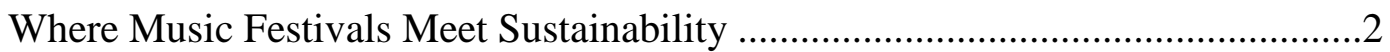

Defining Terms: Sustainability and Sustainable Event Management......................8

The Value of Investing in Sustainably Managed Music Festivals..........................10

The Development of a Sustainable Economy ..............................................11

The Expansion of Sustainability Education ..............................................12

A Need for Sustainable Event Management Strategies of Music Festivals............14

Music Festivals of the United States.......................................................14

Music Festivals in Europe and Australia ..................................................15

Standards and Certifications .................................................................16

Change for Sustainability..................................................................18

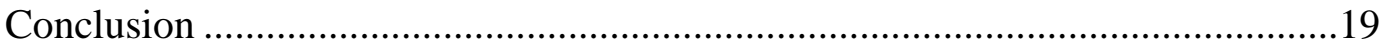

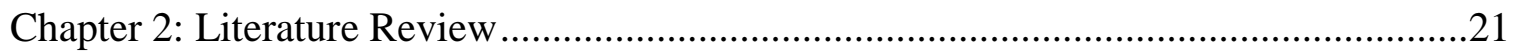

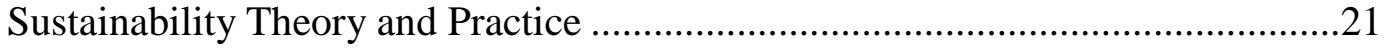

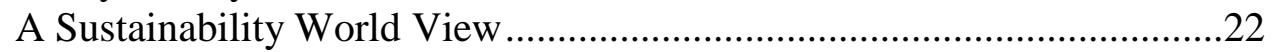

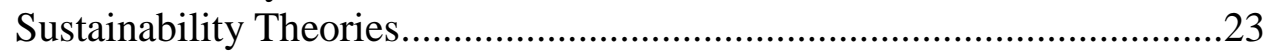

Sustainability Practices .......................................................................22

Environmental Sustainability Practices .......................................26

Social Sustainability Practices ....................................................28

Economic Sustainability Practices ...............................................22

Sustainability Education ...........................................................................

The Convergence of Events and Sustainability …………….................................35

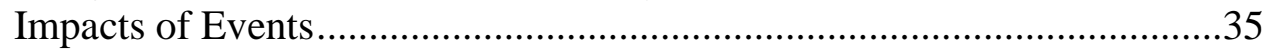

Events as Public Good ...............................................................39

Movement toward Sustainable Event Management ………………….......41

Existing Strategies of Sustainable Events ................................................43

Organizational Change for Sustainability ..........................................................4

The Nature of Organizations and Change................................................46

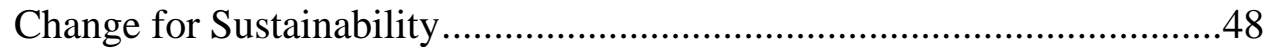

A Shared Vision ........................................................................

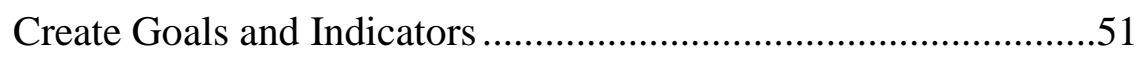

Changes in Basic Operations .....................................................52

Redesign Processes and Systems ..............................................52

Innovation ........................................................................ 
Restructure and Rebuild Business Models .................................53

Organizational Culture Change for Sustainability .................................53

Conclusion

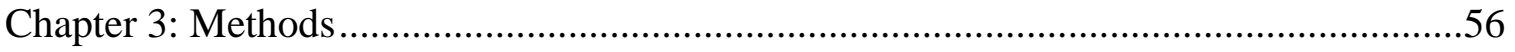

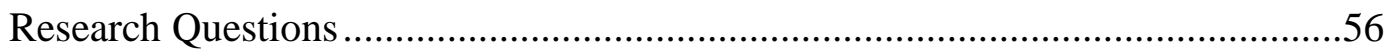

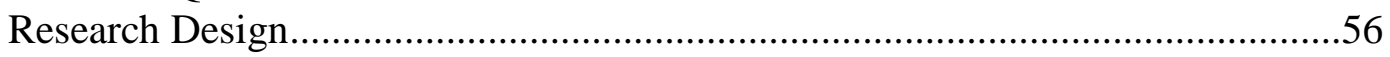

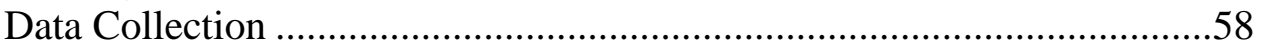

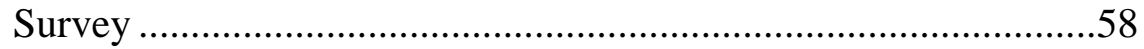

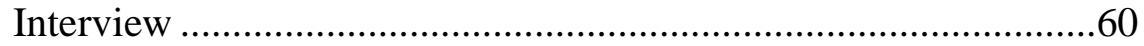

Research Participants ...............................................................61

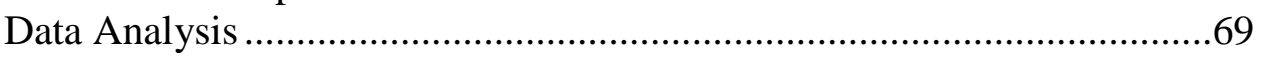

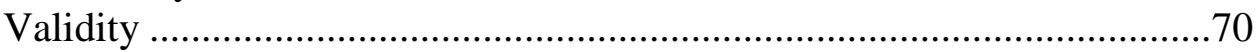

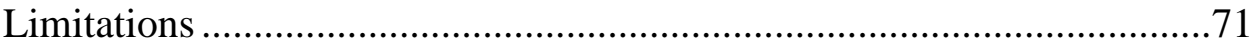

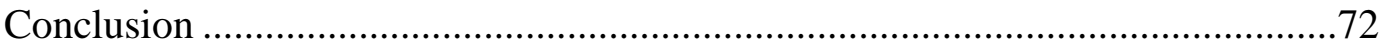

Chapter 4: Results ....................................................................................... 73

What are the Barriers Associated with Sustainable Event Management

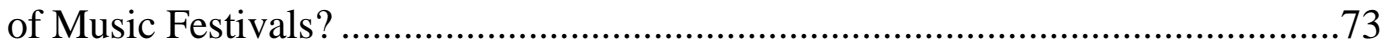

Cost-Prohibitive Sustainability Solutions ...........................................74

Implementation of Sustainability Practices and Methods........................76

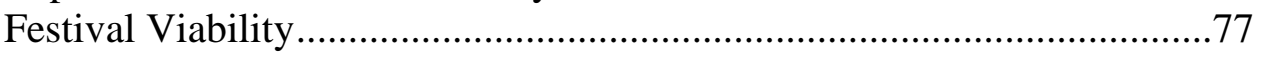

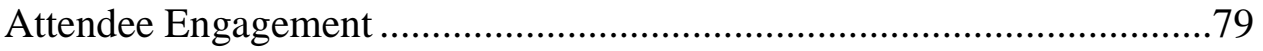

Internal Support, Commitment and Priority ..........................................8

Infrastructure and Local Resources ..................................................81

Government Support ......................................................................82

What are the Success Factors Associated with Sustainable Event Management

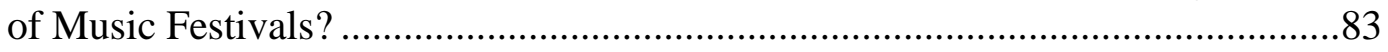

Including Sustainability in Festival Goals ..........................................84

Understanding Context, Relationships and Networks ..........................85

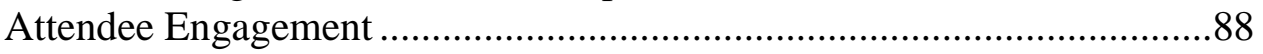

Support from Top Management and Decision Makers ............................89

What, Specifically, Do Music Festival Organizers Need to Improve

Sustainable Event Management of Music Festivals?...........................................90

Improved Understanding of Sustainability Practices and Methods ...........90

More Accurate Perception of Sustainable Event Management ................91

Improved Sustainability Standard for the Sector .................................93

Conclusion

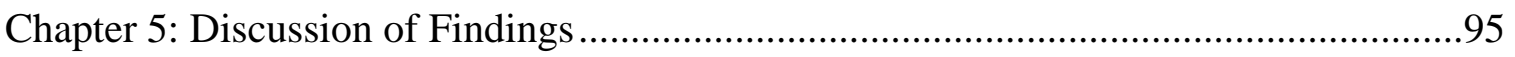

Recommended Strategies .............................................................................96

Use Sustainability Framing and Long Term Planning...........................96

Exercise a Holistic Scope....................................................................100

Invest in Attendees with Sustainability Education ..............................102 
SUSTAINABLE EVENT MANAGEMENT

Share Information about Sustainability Solutions ...............................106

Cooperate to Strategically Build Demand and Reduce Costs.................109

Form an Organizing Body or Alliance...............................................110

Create a Sustainability Rating and Certification System .......................112

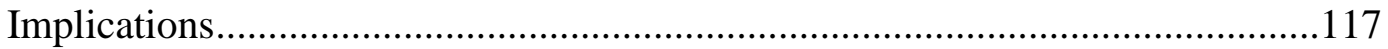

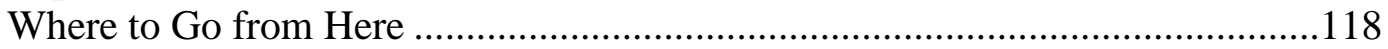

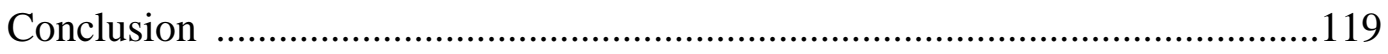

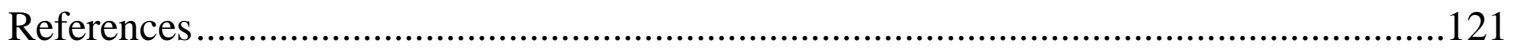

Appendices

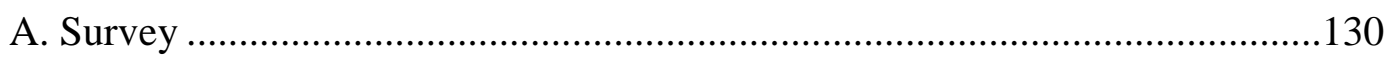

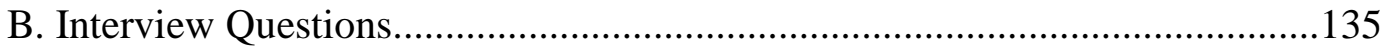




\section{List of Tables}

Table

Page

1 Festivals Represented in Study ...

2 Participants in Interviews... 


\section{List of Figures}

Figure $\quad$ Page

$1 \quad$ Musical Genres of Festivals Represented in Study........................................62

$2 \quad$ Attendees of Festivals Represented in Study .............................................63

$3 \quad$ Kinds of Festival Production Represented in Study ......................................64

$4 \quad$ Sustainability Education and Training of Study Participants ............................67

$5 \quad$ Analysis of the Barriers Associated with Sustainable ........................................74 Event Management of Music Festivals

6 Factors that May Improve Sustainable Event Management ..............................84 


\section{Chapter 1: Introduction}

There is a magic in music festivals. Different music connects to different people, but it connects people's hearts and their heads. People can be motivated in a very fundamental and instinctive way to want to make changes, be sparked to pursue different opportunities, look at the world around them, and feel the power to be part of the group. You realize you aren't alone, and you have the ability to work together. You don't have to accept everything in the world- you can change it. (Chris, personal communication, March 9, 2011)

As conveyed in this quote, music festivals can be very powerful forces for inspiration, motivation and awakening change for a better world. They have long been venues for human gathering, connection and celebration. They also have a unique ability to transcend individual and generational differences to bring people together through common passions. Music festivals open people's hearts, stimulate joy and provide opportunities for being and belonging. When festivals carry such great potential for betterment, it is strange that they largely go understudied and underutilized (Arcodia \& Whitford, 2006). One valuable use of music festivals is their contribution to the transition of sustainability.

As a lifelong festival patron and participant, I have always been fascinated by the transformative power of music festivals to inspire authentic, soulful and deeply humanizing experiences. It wasn't until I took on the role as the sustainability coordinator of a regional music festival that I began to truly understand the curious but remarkable connection between music festivals and sustainability. This particular 
festival was producing massive amounts of waste with zero recovery efforts, burning hundreds of gallons of diesel with zero efficiency or alternative energy efforts, throwing a festival in majestic natural spaces with zero stewardship efforts, and maintaining few positive relationships with the host community. Through my work to turn these negative impacts into positive ones, I experienced firsthand both the opportunities and challenges associated with integrating sustainability awareness, design and decision making into music festivals. With an expanding interest, I began to explore sustainable event management through different perspectives, cities and kinds of events. Finally, I took on the study of music festivals and sustainability academically to further investigate this connection and explore ways to help event organizers improve sustainable event management of music festivals. This thesis is the outcome of that exploration.

\section{Where Music Festivals Meet Sustainability}

The ability of music festivals to inspire awareness and activism in people is fundamentally necessary to the journey toward sustainability. The urgency of sustainability is clear whether society chooses to acknowledge it or not. In a time in which life has become more globalized and digitally connected than ever before, communities have become more fractured and social fabrics more fragmented. Power and economic shifts over the past decades have left the United States with greater inequity and economic disparity since the Gilded Age of the late $19^{\text {th }}$ Century (Fraser, 2008). Ecosystems are being degraded and driven closer to collapse, and the global climate is swiftly shifting into unprecedented variance (Millennium Ecosystem Assessment, 2005). Cultures far and wide are being homogenized in the wake of 
modernization, and local knowledge is being lost beneath strip malls, parking lots and suburban sprawl. General happiness in the United States has not improved over the past three decades, despite economic growth, swanky technologies, and accessibility of more, cheap goods (Easterbrook, 2003). The near future promises fewer natural resources to be shared amongst a greater population, poverty and food scarcity, insufficient water and sanitation, and mass movements of people (Millennium Ecosystem Assessment, 2005). Global modern civilization has created ways of life that are unsustainable. Without necessary precautions, these conditions of un-sustainability will transform the planet into an uninhabitable place for human civilization and debilitate societies so that they are unable to handle the critical challenges of this time.

As society strives to move forward in the transition to greater sustainability, it is important to remember the shared humanity of all people. The uncharted journey toward sustainability is a difficult one. It consists of sustaining human civilization, cultures and knowledge, as well as the planet with its biologically diverse life and ecosystems intact. As times become more testing, people need experiences that are acutely human to connect them to their roots and to one another. People are in need of celebrating their common humanity and diversity, their art and their joy. Music festivals can fill this need as they are a unique phenomenon that build human connection and strengthen solidarity. Rifkin (2009) asserts that to champion the challenges of sustainability, modern civilization must transition to an Empathetic Civilization. Rifkin explains that the assumptions that have guided the construction of modernization, that humans are innately self-interested, violent, aggressive and individualistic, are false and consistent with the 
world view that has driven modern societies to un-sustainability. Rifkin argues that humans are actually soft-wired for natural empathetic sociability. The transition to this empathetic awakening requires an embrace of human companionship, attachment, affection, and belonging. These essential elements of an empathetic civilization are aligned with the core of festival celebration. Music festivals are a natural and renewable power that can help people remember and recharge their basic humanness. Remington (2003) describes the power of festivals:

There is a 'crisis-connection' in the modern world and it is becoming ever more important that leaders in government, business, the arts and other disciplines recognize the power of celebration to renew our sense of community .... Festivals are a way of being, in which individuals can safely be themselves, while simultaneously being with many other types of cultures, personalities, and stages of development. In this and many other ways, festivals build community, diversity, tolerance, and positive values like sharing, helping, contributing, and being a part of the community. (p.1)

Festivals can teach modern society the positive values that are needed to strengthen its collective communities as it engages the journey toward sustainability. Music festivals in particular have a unique way of rousing and connecting people's souls. Shahjahan (2004) asserts that people need stronger spirits to gain the courage to speak and act on the truths of critical issues such as those surrounding sustainability, and "we cannot achieve it by mobilizing people's brains, but rather we need to mobilize their spirits, their bodies and their hearts" (p. 305). Music has historically had the power to stimulate people at a very 
deep and powerful level which is the kind of awakening that is necessary to people around the challenges of sustainability.

At their finest, music festivals provide profound positive benefits to society that are integral to a sustainable world. They can be significant assets to sustainability in five key ways. First, a very popular benefit of music festivals is their ability to support economic development of host communities. They bring massive revenues to host cities, support urban renewal, and increase tourism, job provision and other commercial outcomes (Dwyer, Mellor, Mistilis \& Mules, 2000). Second, music festivals can preserve and exercise a city or region's social capital through civic engagement, public celebration, and developing community resources, cooperation and cohesiveness in the host community (Arcodia \& Whitford, 2006). Moreover, music festivals have historically provided important societal value as venues for political communication, exchange of ideas and social change (Sharpe, 2008). Third, they have a unique ability to build community, support a community's sense of place and identity, and regenerate authentic values and experiences for host communities (Karlsen \& Brandstrom, 2008). Fourth, many music festivals are developing successful and innovative ways to incorporate environmental stewardship and educational techniques to bring awareness and activism to event attendees and host communities alike (Laing \& Frost, 2010). Fifth, as the digital age has transformed the music industry, live music festivals are becoming increasingly important to the music economy and to the livelihoods of the growing base of independent musicians and artists (Holt, 2010; Sen, 2010). These five benefits demonstrate the significant value of music festivals by supporting sustainable 
development and preserving healthy and desirable features of society. We do not need to start from scratch or depend on the invention of new technologies to build a sustainable world. Rather, we must invest in that which we want to sustain and leverage it to expand sustainable development. In doing so, we can collectively identify and phase out that which is less desirable and unsustainable to society.

Unfortunately, these important benefits of music festivals are often encumbered by their negative impacts. Music festivals often carry enormous ecological footprints by consuming massive amounts of energy, water, food, and natural resources, while producing significant waste and carbon emissions (David, 2009). They can put great pressure on host communities' local infrastructure, facilities, and physical spaces, making them compete for critical resources (David). Festivals can become overly commercialized and have been criticized for undermining local culture, traditions and identity with commercial ideals (Arcodia \& Whitford, 2006). Festivals have also shown to bring negative social impacts to host communities like over-consumption, substance abuse, increased criminal activity, negative health effects, community alienation, or breaking of social networks (Getz, 1997; Smith, 2009). Mega-events have also come under great criticism for launching city development that is neither socially nor economically sustainable and doesn't consider the long term benefits of the host community (Smith). There exists an interesting relationship between the positive and negative impacts of festivals, and each festival demonstrates this relationship differently. However, when these negative impacts are mitigated and positive impacts nurtured, music festivals have great potential to become positive forces for betterment. 
Although the sustainability agenda of the $21^{\text {st }}$ century may seem daunting, it is critical to remember that the challenges of this era are time sensitive. The time for addressing sustainability is now. Today there is a need for as many catalysts as possible inspiring, innovating and activating the transition to improved sustainability. This is where music festivals can play a unique and important role. Music festivals have a multitude of wonderful benefits and values that contribute to sustainable development and support a healthy and desirable world. However to reach this greater potential and become real agents in the movement toward sustainability, music festivals must be appropriately designed, envisioned and managed for sustainability. Successfully mitigating the negative impacts and cultivating the positive impacts of music festivals is no easy feat. Even so, many music festival organizers are already making terrific strides in this direction, and there is much to be learned from their experiences and perspectives around sustainable event management. It is imperative to understand the challenges and successes that music festival organizers face in moving their festivals toward sustainability. Only with this understanding can effective strategies be identified to guide music festival organizers in the adoption and expansion of sustainable event management. A study by Brooks, O'Halloran and Magnin (2007) found that music festival organizers are central connectors between key stakeholders and are crucial leverage points for moving music festivals toward sustainability. This means that music festival organizers serve as ideal points in system intervention where small shifts can create big changes (Meadows, 2008). Therefore, by identifying strategies that will 
specifically help event organizers engage and improve sustainable event management, music festivals will more quickly be able to reach their greater sustainability potential.

\section{Defining Terms: Sustainability and Sustainable Event Management}

To fully understand the concept of sustainable event management, it is important to first define the term 'sustainability,' as it is widely interpreted and continually evolving. Most commonly defined, "sustainable development meets the needs of the present without compromising the ability of future generations to meet their own needs" (World Commission on Environment and Development, 1987, p. 43). This definition has a very broad scope and makes sustainability a concern to every faction of the human and natural worlds. Although generally accepted, this definition can be elusive and abstract when engaging sustainability in day-to-day life. In both theory and practice, sustainability has been observed as a concept, process and goal. While this understanding is more explanatory, there is still a need for further clarification of the dimensions of sustainability. This thesis strives to maintain a holistic interpretation of sustainability and conceives it within the environmental, social and economic dimensions. Recognizing sustainability in these three domains is consistent with the triple bottom line (TBL), a popular framework for measuring the progress of sustainable development in three equal parameters, often cited as the three P's: people, profit and planet (Edwards, 2005). The triple bottom line is most well known within organizations striving to achieve organizational or corporate sustainability. Additionally, these three domains of sustainability were outlined by the United Nations at the Earth Summit in Rio in 1992, when the original international guidelines for sustainable development were 
created (Edwards). This understanding of sustainability can now be used to define the term 'sustainable event management.'

Sustainable event management is the convergence of sustainability with the project planning process of event management (Katzel, 2007). A sustainably managed event is one in which sustainability awareness, design and decision making are fully integrated into its management logistics, operations, and production. Sustainable event management has been evolving over the past two decades and is rapidly growing in recognition, both in the national and international event industries. Event coordinators increasingly seek to improve the sustainability credentials of events, and sustainable event discussion has become popular amongst the media and public (Laing \& Frost, 2009). Sustainability practices have begun to take hold in all kinds of events including conferences and meetings, trade shows and expositions, mega-events, sporting events, festivals, religious or cultural celebrations, and community and civic events (Sustainable Event Alliance, 2011). Though sustainable event management continues to grow in popularity, it is not yet common practice. There are very few forces or mechanisms driving the widespread adoption and expansion of sustainable event management to become common practice throughout the music festival community. Therefore a need exists to identify strategies that will help event organizers engage and improve sustainable event management of music festivals.

For sustainable event management to become more widely adopted there should be greater clarification of the term. Sustainable event management is a relatively new trend, and there still exists much ambiguity and interpretation around its concept. For 
example, sustainable event management is sometimes referred to as 'event greening.' The terms 'sustainable event,' 'conscious event,' 'responsible event,' or 'green event' have also been used to describe events that have taken this route. Generally the term 'greening' has an environmental connotation and is used to describe the process of transitioning a product, service, activity or organization into a more environmentally sustainable version. The Sustainable United Nations unit of the United Nations Environmental Programme (2009) provides this definition for a 'green event:' "A green event is one designed, organized and implemented in a way that minimizes negative environmental impacts and leaves a positive legacy for the host community" (p. 9). This thesis suggests that the concept of sustainable event management can be stretched to embody a more holistic meaning of sustainability and should equally embrace at least its social, economic and environmental dimensions. Therefore, this thesis refrains from using the terms 'sustainable event management' and 'greening' interchangeably. Only by striving to recognize its holistic meaning can the concept, process and goal of sustainability reach its greatest potential. Similarly, only by embracing a holistic understanding of sustainable event management, can music festivals embody their greatest value and benefit. These defined terms lay a foundation for moving forward to identify strategies for sustainable event management of United States music festivals.

\section{The Value of Investing in Sustainably Managed Music Festivals}

When strategizing for a sustainable and desirable future, it is important to invest in sustainable solutions. In his essay, Solving for Pattern, Wendell Berry (2009) teaches that a good solution is one that solves more than one problem while not creating any new 
problems. Therefore, poor or premature solutions produce a temporary good while creating more problems in the long run. This thesis suggests that sustainably managed music festivals are good solutions for the betterment of society, can fill an important niche in a sustainable future, and can provide great value if invested in.

The development of a sustainable economy. Sustainably managed music festivals can be vital players in the development of a new and sustainable economy. It is becoming well-accepted that the planet cannot sustain the existing growth and consumption based economy, and as such, there has been discussion as to what the future economy will look like. The limits to growth are now being confronted, and scholars warn that conscious and active decisions must be made in order to transition to a more sustainable economy (Meadows, Randers \& Meadows, 2002). The transition will require shifting the growth-based economy to one that progresses quality of life and exists within the carrying capacity of the planet's ecosystems (Daly, 1993). The current economy is dependent on consumerism and a culture of consumerism that ties happiness to material pursuits which represent social status and display (Jackson, 2009). The new economy will need valuation redirected to intrinsic sources such as family, shared experience and art, which exist outside the realm of the market. The United Kingdom's Sustainable Development Commission commissioned a paper entitled Prosperity Without Growth that examines the transition and conditions of a new and sustainable macroeconomic system. In this paper, Jackson (2009) asserts that in this transition, prosperity must be redefined from growth through material consumption to human well-being, sense of belonging and trust in community. These ideals can be supported by sustainably 
managed music festivals. Additionally, a founding concept of the new economy is the production and sale of de-'materialized' services rather than material products. Jackson suggests that the recreation and leisure sector ought to be a prime candidate for expansion of the new economy if the sector weren't so carbon and energy intensive. Music festivals are almost entirely service-based works of the economy. If event organizers are able to mitigate their heavy ecological footprints and learn to limit their consumption through sustainable event management, they can be vital players in a sustainable new economy.

The expansion of sustainability education. Sustainably managed music festivals can be powerful drivers of sustainability education through awareness, design and experience. An intrinsic feature of music festivals is their ability to inspire and motivate (Jones, 2010). The utilization of music festivals as tools inspire and motivate people around environmental awareness is beginning to grow in popularity (Laing \& Frost, 2009). Additionally, music festivals have been produced for the purpose of generating awareness around other sustainability issues, such as climate change, sustainable lifestyles, healthy living, and a variety of social causes (Jones, 2010). The awareness generating influence of live music festivals was internationally recognized when the United Nations Environment Programme developed the United Nations Music and Environment Initiative. The aim of the initiative is "to use the popularity of music to promote environmental awareness and respect for the environment among the public, especially young people; and to assist in the process of 'greening' the music and entertainment industry" (Jones \& Scanlon, 2010, p.4). The initiative recognizes that "music is one of the most powerful mediums to communicate environmental awareness 
to billions of people worldwide - irrespective of race, religion, income, gender or age" (Jones \& Scanlon, 2010, p.4). As such, this initiative is an unprecedented, international cooperation of music festivals and is taking leadership to influence the expansion of sustainable event management.

Beyond their ability to generate awareness, sustainably managed music festivals can create sustainability education through the design and experience of the festival itself. The design, architecture and operations of physical spaces create a sort of "public pedagogy" that communicates messaging to those who interact with them (Orr, 2004, p. 112). Orr (2004) asserts that the built environment has hidden curriculum and can teach about the power dynamics of human and ecological relationships, awareness for energy and materials, and human ingenuity for creating sustainable solutions. When music festivals and venues are designed and operated in ways that fully align with sustainability, they can give people a safe haven in which to experience, engage and learn about sustainable infrastructure, culture and choices. Music festivals are extremely participative events and provide attendees with powerful and interactive experiences. When these experiences take place within sustainably designed architecture and spaces of music festivals, attendees can experience a unique kind of sustainability learning. By investing in sustainably managed music festivals, there is great opportunity to compound the power of sustainability education and strengthens society's capacity to build movement toward a more sustainable future. 


\section{A Need for Sustainable Event Management Strategies of Music Festivals}

With such great potential benefits of sustainably managed music festivals, how can this incredible power be harnessed? To fully activate these benefits, sustainable event management needs to be improved and widely adopted by music festivals as common practice. This movement is slowly underway, but music festival organizers are in need of strategies to speed this process along and catalyze their creative expertise. To effectively identify such strategies, it is important to first understand the background and context of music festivals.

Music festivals of the United States. Music festivals have long been agents for preserving and exercising heritage and arts in the United States (Latham, 2002). Originating music festivals in the United States captured, documented and celebrated United States music and culture (Latham). For example, the Old Time Fiddlers' Convention founded in 1924 in North Carolina was the first to focus on indigenous American music. The Newport Jazz Festival in 1954 in Rhode Island was one of the first American jazz festivals (Latham, 2002; Sadie \& Tyrrell, 2001). Pop and rock festivals began to unfold after the Monterey Pop Festival in 1967 and Woodstock in 1969. Like their predecessors, these early rock festivals displayed and documented transitioning American music and culture and created a template for modern music festivals. The accessibility of international travel and ease of digital communication have allowed festivals to reach unprecedentedly large and diverse audiences. Modern music festivals highlight specific composers, musical genres, artist workshops, and market packages that promote the arts and tourism in equal degree (Latham). Today the typical music festival 
occurs annually over several days in a fixed season of the year, in a single city and sometimes in a single outdoor venue, and audiences range from hundreds to hundreds of thousands (Sadie \& Tyrrell). Compared to other kinds of events in the event industry, music festivals appear to be more widely engaging sustainability practices. Music festivals are beginning to adopt creative audience engagement programs, and influential organizations such as Rock the Earth, Reverb, and the Green Music Group have been launched to help bring environmental awareness to the music industry (Jones \& Scanlon, 2010). Overall, though, there is little documented information about the state of sustainability or sustainable event management of United States music festivals.

Music festivals of Europe and Australia. The state of sustainable event management of music festivals in Europe and Australia is arguably further developed and more organized than that of United States music festivals. There are many organized efforts and bodies in Europe to assist music festivals in their transition to sustainability. Julie's Bicycle is a UK-based alliance of professionals and researchers committed to organizing the music industry around greening efforts (Julie's Bicycle, n.d.). A Greener Festival is a UK-based organization that awards music festivals which have achieved environmental sustainability accomplishments (AGreenerFestival, Ltd., n.d.). Yourope is a European Festival Association that awards Green'N'Clean awards to festivals that demonstrate noteworthy greening initiatives (Yourope, n.d.). These are just a few of the most influential organizations.

There also appears to be strong influence of organized sustainable event management efforts in Australia. The Sustainable Event Alliance is an Australian- 
founded, international, event-industry, professional association that shares information and resources to improve sustainability practices in events (Sustainable Event Alliance, n.d.). Additionally, the bulk of academic literature concerning events and sustainability appears to be produced out of Australia which demonstrates a very concentrated interest in the topic. While the United States is developing independent, innovative projects, it doesn't seem to have the same organized guidance or support of cross-entity alliances that Europe and Australia do. This reveals a need to understand the barriers and success factors that Untied States music festivals face to determine specifically what event organizers need to better move their music festivals toward sustainability.

Standards and certifications. There not only appears to be more organized support for music festivals in Europe and Australia, but most of the standards and certifications systems that are being created in the event industry are developing outside the United States. Standardization of sustainability measures brings uniform definition, metrics and authentication to systems in relative disorganization. Standards are being developed to provide guidance and quality to the progression of sustainability processes and practices as they become more common practice. An event that has implemented a charitable giving program cannot be considered the same degree of sustainability as an event that has implemented extensive environmental, social and economic sustainability strategic design and long-term planning. Sustainability standards minimize confusion and provide common language and order to these issues. Several organizations have developed or are in the process of developing standards for sustainable event management. For example, The British Standards Institution developed the 
Sustainability Management Systems for Events, the BS8901, in 2009 (British Standards Institute, 2010). This standard is being used to guide the development of a standard by the International Organization for Standardization, called ISO 20121 Sustainability in Event Management (International Organization for Standardization, 2011). This standard is due to be released alongside the production of the London Olympics in 2012. Unlike other standards that provide certain objectives, ISO 20121 is a sustainability management system that supports the use of other standardizing tools or indicators for reporting. Julie's Bicycle has developed Industry Green, a UK-based certification that demonstrates carbon emissions reductions in the music industry (Julie's Bicycle, n.d.). Lastly, the Convention Industry Council's Accepted Practices Exchange (APEX) and Meeting Professionals International recently developed environmentally sustainable standards for meetings and conferences that are being reviewed for standardization as of early 2011 (Convention Industry Council, 2010). While the APEX standard is based in the United States, it has little applicability to music festivals as it is being designed specifically for meetings and conferences. The development of these different standards is a remarkable movement toward encouraging common practice of sustainable event management. As of yet, none of these standards are widely accessible or accepted by United States music festivals. In addition to these formalized standards, dozens of 'greening guides' have been written by different parties to help music festival organizers take up sustainability practices. However, most of these provide only surface-level objectives and lack the systemic and strategic guidance necessary to address the particular barriers faced by music festival organizers. This further demonstrates the need for strategies that will 
specifically assist United States music festival organizers in sustainable event management.

Change for sustainability. Without much guidance, music festival organizers are implementing a hodgepodge of sustainability projects under a growing pressure to become greener (Laing \& Frost, 2010). Music festival organizers are not alone in confronting the challenge of becoming more aligned with sustainability. Organizations such as corporations, institutions, and public and private entities are engaging in varying processes and practices of organizational change for sustainability as well (Lubin \& Esty, 2010). As of yet, few practical implications or road maps have been developed to help organizations become more sustainable (Jabbour, 2008). Consequently, many organizations are experimenting with trial and error or launching a medley of initiatives in the name of 'sustainability' without a clear understanding of the direction in which they are headed (Lubin \& Esty). Researchers and writers are beginning to pull from organizational change theory and compile case studies and papers to draw lessons on how organizations are best transitioned to sustainability (Harris \& Crane, 2002). These lessons can be borrowed to guide the development of strategies for sustainable event management and will be further explored in the following chapter. As the transition to sustainability is not simple, it makes sense for event organizers to seek guidance from other disciplines as they work to better move their music festivals toward sustainability. 


\section{Conclusion}

The challenges that define the $21^{\text {st }}$ Century are time sensitive, and activating the transition toward sustainability is urgent. Sustainably managed music festivals have a multitude of benefits and can be utilized to aid society in this great transition. They celebrate humanity, inspire positive values and can motivate people to understand and engage the world around them. Additionally, sustainably managed music festivals can be good societal investments by contributing to the new economy and inspiring sustainability education. However, for this great potential to be realized sustainable event management of music festivals must become widely adopted as common practice. This means that sustainability awareness, design and decision making must be fully integrated into music festival management logistics, operations, and production to effectively mitigate the negative impacts of music festivals while cultivating the positive ones. This is no easy feat, but the music festival community is already heading in this direction. To drive the adoption and expansion of sustainable event management, there is a need to first understand the challenges and successes that United States event organizers face in their efforts to move music festivals toward sustainability. With this greater understanding, specific strategies can be identified that will equip event organizers to improve the triple bottom line sustainable event management of their music festivals.

This study is centered on developing a better picture of the state of sustainable event management of United States music festivals. The purpose of this study is to more succinctly understand sustainable event management through event organizers' experiences and perspectives. With an understanding of the barriers and success factors 
that event organizers face moving their music festivals toward sustainability, strategies can be identified to improve sustainable event management. Specifically, this study examines the following research questions: What are the barriers and success factors associated with the sustainable event management of music festivals? What, specifically, do music festival organizers need to improve the sustainable event management of their festivals? The methods used to answer these research questions comprised of a survey and interviews. Surveys were gathered from thirty event organizers who were responsible for sustainability decision making and coordination for a United States music festival. Then, five of the survey participants were interviewed to supplement and expand the survey data with an additional qualitative analysis. From the study results, seven recommended strategies are presented to help event organizers improve sustainable event management of music festivals.

The second chapter of this thesis reviews the literature in the areas of sustainability theory and practice, the convergence of events and sustainability, and organizational change for sustainability. This chapter introduces important concepts, provides an overview of previous research, and borrows lessons from other disciplines to establish a strong foundation for this study. The third chapter presents the methodology of this study, including the research design, validity, limitations and significance of the study. The fourth chapter presents the results of the data collection and analysis. The fifth chapter discusses the results and presents recommended strategies and a final conclusion. 


\section{Chapter 2: Literature Review}

When envisioned, designed and managed for sustainability, music festivals have much to contribute to the transition of sustainability. For sustainable event management to become common practice and this greater potential to be realized, music festival organizers are in need of strategies to help them improve sustainable event management. This chapter reviews existing literature of relevant topics to provide a background of important concepts, previous research and lessons borrowed from other disciplines. First, this chapter will review literature pertaining to sustainability theory and practices. This section provides a background of a sustainability world view, important theories and sustainability practices, and an overview of sustainability education. Next, this chapter will review existing literature on the convergence of events with sustainability. This section provides literature on the impacts of events and gives an overview of movement toward sustainable event management and existing strategies of sustainable events. The last section of this chapter will review literature on organizational change for sustainability. This section discusses organizational change theory and then compiles a synthesis of the stages of organizational change for sustainability. This chapter will provide the necessary background information and context to build an understanding around sustainable event management and thereby lay the foundation necessary to ground this study.

\section{Sustainability Theory and Practice}

To identify strategies that will help event organizers improve the sustainable event management of United States music festivals, it is important to first examine 
sustainability in theory and practice. To improve sustainable event management, event organizers must continually design sustainability solutions to fill the space between where music festivals are now and a more sustainable and desirable future. To ensure that sustainability solutions are effective, it is imperative that the theories and practices that make up the concept, process and goal of sustainability are well understood. This section will walk through the literature that underpins this notion.

A sustainability world view. To understand the concept of sustainability, it is necessary to first understand the founding world views of modern culture that have put civilization on a trajectory of un-sustainability. Architected by thinkers Descartes and Galileo, the founding ideals of Western civilization have historically nurtured a world view that is mechanistic and reductionist (Sterling, 2001). Contrary to many indigenous world views, the classical Western world view favors disconnection, categorization, and separation of humans from nature, nature from its intrinsic value, and a human's mind from his/her body (Orr, 2004). It breaks wholes into fractions, study into disciplines, and creates a constant sense of 'the other.' It is born in linearity and perpetuates dichotomies such as cause/effect, present/future, and human/nature (Sterling). This world view has given way to a modern culture characterized by destruction, oppression, and domination over both nature and the 'other'.

The utilitarian and industrial economic philosophy of the $20^{\text {th }}$ century has also contributed to the world view that founds modern culture. The growth-centered and consumption-based global economy is inherently unsustainable (Meadows, Randers \& Meadows, 2004). For more than 30 years, select economists have warned of the limits to 
economic growth in our finite world, but modern culture has continued on a linear path consuming natural resources faster than they can be restored and releasing wastes and pollutants faster than the Earth can absorb them (Meadows et al., 2004). Daly (1995) warns that "population growth and production growth must not push us beyond the sustainable environmental capacities of resource generation and waste absorption" (p. 3). With failure to acknowledge limits to growth, many warning signs have emerged including natural resource scarcity, global warming and degrading ecosystems, that will ultimately lead to global environmental and economic collapse if uncurbed (Meadows et al.). However clear the warnings may be and however many warning signs there are, modern culture is at a loss to fully confront the contradictions in its economic philosophy. While all natural systems, such as carbon cycles, water cycles, and nitrogen cycles are cyclical, modern culture continues to expect its economic system to perpetuate in linear and uninterrupted growth. Modern culture has yet to fully understand that its economic expectations are directly conflictive with natural systems, and it cannot continue to live against the laws of nature (Orr, 2004). There are many cultural contradictions and conventional assumptions that lie deeply embedded in the world view of modern culture and perpetuate unsustainable ways of life. Leading thinkers suggest that the key to finding solutions to un-sustainability lie in challenging these assumptions and views of modern culture's ways and systems (Evans, 2010).

Sustainability theories. In the past decades, new theories have developed that challenge these assumptions and propose alternative ways of thinking. Capra (2002) suggests that by understanding the natural design and processes of living systems, 
humans can reframe their thinking and reorient their own systems into the broader context of natural systems. This deepening understanding of the interdependency of human and natural systems is allowing thinkers to better craft strategies and solutions to address issues of un-sustainability. For example, Berkes and Folke (1998) have created an interdisciplinary approach to environmental management practices by linking social and ecological systems and have declared the delineation between these systems "artificial and arbitrary" (p. 4). Systems theory introduces a non-linear approach to problem solving in which systems are conceived as dynamic and whole, dependent to all others, and greater than the sum of their parts (Meadows, 2008). Complexity theory, mathematically understood as non-linear dynamics, was developed in the 1980s to better understand the complexity of living systems (Capra). This theory expands on systems thinking and has given way to new conceptualizations of consciousness and ties between biological life and social institutions (Capra). Panarchy theory describes the evolving relationship between social and ecological systems and presents a model where systems are nested within one another and interlinked in never-ending adaptive cycles of creative destruction and renewal (Hollings, 2001). Until the past few decades, environmental, social and economic issues were viewed as separate and studied independently from one other (Berkes \& Folke). The development of these theories is beginning to shift conventional frameworks to a more interconnected and trans-disciplinary orientation of sustainability. The concept of sustainability embodies these ideas and supports a shift in world view from mechanical and reductionist to relational and ecological (Sterling). Today, sustainability is a comprehensive and holistic approach to tackling the complex, 
real world issues of this era. Although the descriptions of these theories are brief, it is important to acknowledge their significance to the development of sustainability thought. This is because good design and implementation of solutions requires good sustainability thinking.

Sustainability practices. As we consider how to improve the sustainable event management of music festivals, we must also understand how sustainability is approached in practice. This section will discuss sustainability practices on an organizational level. For the purpose of this thesis, organization is defined as a social arrangement with the purpose of distributing tasks for a collective goal (The Oxford American College Dictionary, 2002). Accordingly, this thesis uses the terms organization, company, and corporation interchangeably and looks past whether the organization functions in a for-profit or not-for-profit capacity. Sustainability practices of organizations will be discussed in the domains of environmental, social and economic for the sake of clarity. However, it is important to remember that these three dimensions of sustainability are interconnected and must be addressed concurrently to achieve effective solutions. The Brundtland Commission realized in 1987 that "compartments have begun to dissolve. This applies in particular to the various global 'crises' that have seized public concern . . . . These are not separate crises: an environmental crisis, a development crisis, an energy crisis. They are all one" (World Commission on Environment and Development, 1987, p.4). Therefore, it is important to remember that these dimensions cannot be separated as music festival organizers implement sustainability practices within their festivals. 
Environmental sustainability practices. The notion of an Industrial Metabolism was first developed by Ayers (1989) to show the relationships between ecological and industrial systems and is still applicable to environmentally sustainable organizations today. It conceives of corporations as living organisms that consume energy and materials to release both desirable outputs, such as goods and services, and undesirable outputs like waste and emissions (Ayers). If corporate organisms consume more energy and materials than can be reproduced or outputs more waste and emissions than can be absorbed by natural environmental cycles, then that corporation's production loop is considered environmentally unsustainable. Dyllick and Hockerts (2002) define environmentally sustainable companies as those that:

use only natural resources that are consumed at a rate below the natural reproduction, or at a rate below the development of substitutes. They do not cause emissions that accumulate in the environment at a rate beyond the capacity of the natural system to absorb and assimilate these emissions. Finally they do not engage in activity that degrades eco-system services. (p. 133)

Therefore, to become fully environmentally sustainable, organizational systems must function collaboratively with environmental systems and exist within their natural carrying capacity.

Environmental sustainability initiatives can be seen as focused on either ecoefficiency or eco-effectiveness (Dyllick \& Hockerts, 2002). Eco-efficiency initiatives increase economic value, primarily through cost savings, while reducing ecological impact and resource intensity. These practices might include waste minimization and 
diversion, energy efficiency, pollution prevention, zero emissions initiatives, water conservation, reduced material consumption, material life cycle assessment, and reduced toxicity (Braungart, McDonough \& Bollinger, 2007; Dyllick \& Hockerts). Ecoefficiency is often cited as the primary business case for corporate environmental sustainability and is a valuable tool for creating relative sustainability improvements (Dyllick \& Hockerts). However, eco-efficiency initiatives alone will not reach full environmental sustainability nor maintain an organizational system safely within the carrying capacity of natural systems (Dyllick \& Hockerts). It is possible for an organization to be as eco-efficient as possible while still depleting ecological resources and systems.

Eco-effectiveness goes beyond eco-efficiency to restore and enhance the natural environment (Young \& Tilley, 2006). It ensures that organizations are life-sustaining, restorative and regenerative rather than depletive of natural resources and systems (Young \& Tilley). Braungart, McDonough and Bollinger (2007) argue that ecoefficiency initiatives are a reactionary, short term approach to minimizing environmental impact, whereas eco-effectiveness practices deal with long-term, fundamental re-design of material flows. Eco-effectiveness practices move the organization toward cradle-tocradle designs of production, cyclical material flow systems, and the maintenance of resource quality and productivity (Braungart et al.). Therefore, it is important for event organizers to think beyond eco-efficiency practices when working to make their music festivals more environmentally sustainable organizations. By bearing in mind a long term perspective, event organizers can create more eco-effective solutions. The 
importance of maintaining a long term perspective is consistent with social sustainability practices as well.

Social sustainability practices. Socially sustainable companies are defined by Dyllick and Hockerts (2002) as those that:

add value to the communities within which they operate by increasing the human capital of individual partners as well as furthering the societal capital of these communities. They manage social capital in such a way that stakeholders can understand its motivations and can broadly agree with the company's value system. (p.134)

This definition of socially sustainability companies references only the social sustainability external to the organization. However, it is important to also include the social sustainability of the internal organization. Specifically, Pfeffer (2010) notes that socially sustainable companies should ensure that management practices have a positive impact on employee physical and psychological well-being. When considering the social sustainability practices of an organization, one must consider the internal impacts on employees and direct stakeholders in addition to the external impacts on host communities, local cities and indirectly impacted communities. Internal social sustainability practices might include the provision of health insurance, health and wellness programs, minimal lay-offs, reasonable work hours, a living wage, and equitable employment and labor practices (Pfeffer). External social sustainability practices will positively contribute to the social sustainability of the organization's host city, particularly in the areas of governance, social and cultural policies, social intrastructure 
and public services, urban land and housing, transport and accessibility, economic revitalization, and the building of inclusive public spaces (Polese \& Stren, 2000). Depending on the scale and impact of the organization, external practices will differ to be relevant to regional, national or international social sustainability.

Corporate sustainability writers have proposed that social sustainability practices of organizations can also be considered efficiency or effectiveness focused (Dyllick \& Hockerts, 2002; Young \& Tilley, 2006). Consistent with environmental sustainability practices, efficiency practices aim to mitigate harmful impacts while effectiveness practices aim to make positive contributions. Young and Tilley (2006) suggest that socio-efficiency practices often take the form of corporate social responsibility programs, because they aim to mitigate a company's harmful social impacts. Corporate social responsibility is usually a commitment to ethical practice and focused on issues of the company's choice (Pfeffer, 2010). While a company may make strong corporate social responsibility commitments, the company may still be responsible for harmful impacts on society as a whole (Young \& Tilley). Socio-effectiveness practices push beyond corporate social responsibility commitments toward an organizational social mission and sustained positive impact on society (Young \& Tilley). Thus, for music festivals to become socially sustainable, event organizers should look past charitable giving programs and exercise social sustainability practices that will leave a positive legacy both internally and externally of the festival organization.

Economic sustainability practices. Economically sustainable organizations are defined by Dyllick and Hockerts (2002) as those that "guarantee at any time cash flow 
sufficient to ensure liquidity while producing a persistent above average return to their direct and indirect stakeholders" (p. 133). To become economically sustainable, organizations must maintain viability within the current economic system from which communities can benefit without putting greater pressure on natural resources (Raj \& Musgrave, 2009). Moreover, economically sustainable organizations must maintain an effective profit while managing several types of economic capital: financial capital such as equity and debt; tangible capital such as machinery, land and inventories; and intangible capital such as inventions, brand, know-how and organizational processes (Dyllick \& Hockerts). The importance of successfully managing economic capital to maintain the economic viability of an organization is well accepted, although not always easily accomplished.

Working toward economic sustainability is the responsibility of everyone. Raj and Musgrave (2009) suggest that organizations must work to become economically sustainable together, and that it will take generations to move past industrial approaches to management and economics. Raj \& Musgrave (2009) further explain that to become economically sustainable, the true impact of organizations should be assessed holistically rather than as separate entities. This means that music festival organizers should assess the impacts of the music festivals as a whole to ensure that the entire music festival community becomes economically sustainable. Additionally, it is important for music festival organizers to employ long term perspectives in sustainable event management to ensure economic sustainability. 
These organizational sustainability practices in environmental, social and economic dimensions are critical for effective sustainable event management solutions to be designed and implemented. Also central to the formulation of sustainability solutions is education. In fact, education has been considered the fourth " $E$ " to complement the "3 E's" of sustainability: equity, environment and economics (Edwards, 2005). Therefore, it is important for event organizers to understand a background in sustainability education. The next section will give on overview of sustainability education and why it is significant to the sustainable event management of music festivals.

Sustainability education. The transition to sustainability requires a collective shift in thinking from that which perpetuates un-sustainability to that which generates sustainability. Similarly, for music festivals to mitigate their negative impacts and cultivate their positive impacts, stakeholders of music festivals must together shift their thinking from that of that of "compete and consume" to that of "care of conserve" (Sterling, 2001, p. 21). Music festivals are already embracing sustainability education techniques to influence attendees, and having a broader understanding of sustainability education approaches will help event organizers improve this effort.

Sustainability education differs from the conventional education paradigm in its engagement with the learner. Learning and curriculum in the mechanical education paradigm is informational, transmissive and prescriptive (Sterling, 2001). Sustainability education aims to not only awaken the learner with new knowledge but seeks to actively engage the learner with emergent and transformative learning. Mckweon (2002) describes the distinction between education about sustainability and education for 
sustainability. In the first, education takes the form of an awareness lesson about sustainability content. In the second, education is a tool used to achieve real sustainable development. This means that sustainability education can be used to develop "learning skills, perspectives, and values that guide and motivate people to seek sustainable livelihoods, participate in a democratic society, and live in a sustainable manner" (Mckweon, p.16). Sustainability education builds learners' capabilities, leadership and contribution to the greater transition toward sustainability. It is important that sustainability learners are educated both about and for sustainability. For example, it is important that each department head of a music festival team to be educated about materials consumption issues, so that each will become an empowered leader who independently makes thoughtful consumption decisions in the event production process. In this way, sustainability education reduces the festival's total materials and resource usage, and the festival's overall sustainable event management is more successful.

The significance of sustainability education can be further demonstrated by three different orders of progressive learning. First order of learning is an acquisition of information and knowledge for instrumental purposes (Sterling, 2001). This kind of learning takes place within accepted boundaries and doesn't challenge the views or values of the learner. For example, this might be learning to do one's taxes, crochet a hat or fix a tire on a bike. Second order of learning involves critical thinking, reflection and challenges the learner's assumptions (Sterling). This kind of learning helps us understand social norms and human relations of the communities and societies in which we live (Cranton, 2002). Third order learning takes place in a deeper level of self- 
awareness and is brought about through critical reflection and self- reflection (Cranton). This order of learning is transformative because it transforms some part of the way the learner sees of the world and invokes new views and ways of doing things (Cranton).

Transformative learning is important to sustainability education because the crisis of sustainability ultimately requires a deep examination of the assumptions and core values that found modern culture. Music festivals are excellent places for transformative learning opportunities because they are able to engage large numbers of people, together in very powerful ways. Transformative learning can occur gradually over time or from a sudden, powerful experience (Baumgartner, 2001). Designing for transformative education is difficult because these experiences generally happen whenever learners are ready. However, transformative learning has several general facets it its progression that can be used to design learning environments to support transformative opportunities (Cranton, 2002). These facets are: a disorienting or activating event that exposes a discrepancy in what a person assumes to be true, articulating underlying assumptions that are largely unrecognized, critical self reflection that examines these assumptions, openness to alternative viewpoints, discourse that explores alternative perspectives, revision of assumptions to make them more justified, and acting on revised assumptions with a transformed perspective (Cranton). Because the phenomenon of music festivals encapsulates these different facets, music festival organizers can aim to design for transformative learning opportunities.

There are several educational approaches that contribute to these three orders of learning and contribute the learner's own sustainable development. Experiential 
education helps learners actively engage, investigate, experiment, critically reflect and construct meaning from their experiences (Higgins, 2009). Another approach is critical social pedagogy, which helps learners understand, analyze and challenge conventional assumptions that are responsible for creating oppression, exploitation and injustice in culture and society (Evans, 2010). Sustainability education should always be grounded in ecological and cultural principles. Capra (2005) suggests that people today are in need of regaining their ecological literacy and should learn to be attuned to food cycles, water cycles, season cycles and all cycles that are interconnected in the planetary web of life. Ecological principles including networks, cycles, solar energy, partnership, diversity, and dynamic balance are vital to our being and survival (Capra, 2002). Lastly, sustainability education must be place-based, contextual, and relevant to local culture. Gruenwald (2005) suggests that sustainability education should be conscious of place because places create human experiences, reflect humans' relationship with nature, and ultimately teach us about the world. Sustainability education is a central vein to the transition of sustainability because it provides a personal angle from which to critically examine and address the challenges of this time.

Sustainability poses a different way of thinking and problem solving from conventional norms. It is important for event organizers to have grounding in the development and interconnections of sustainability theories and practices to craft good sustainability solutions in event management. A background in these areas is necessary to ground this study and effectively identify strategies to improve sustainable event management. Furthermore, a background in sustainability theory supports the rest of the 
literature review, which includes the convergence of events with sustainability and organizational change for sustainability.

\section{The Convergence of Events and Sustainability}

Literature that ties events and festivals to the concepts of sustainability or sustainable development is quite slim. Literature focused on the economic, social, cultural or environmental impacts of events and festivals in any capacity is established primarily in the events and tourism field of study. The literature used in this this is derived mainly from Australia, Western Europe, Scandinavia and South Africa. Very few articles were found from the United States which may demonstrate the country's lack of participation or interest in the field. Getz (2010) has noted that the events literature is missing a sustainability component. While there is much literature on the impacts of events in a developmental capacity, there is a gap in the literature concerning sustainable development. Much of what is emerging in the sustainable event management field seems to have not yet been captured in academic literature.

Impacts of events. There are many scholars working on economic impact studies aimed at assessing the economic value of events and festivals with quantifiable monetary estimates of worth and their economic impact on the host region (Burgman \& Mules, 2000; Dwyer, Forsyth \& Spurr, 2005; Jackson, Houghton, Russell \& Triandos, 2005). Festivals are being used as vehicles to build infrastructure, create jobs, bring in revenue, attract investment, stimulate urban renewal and build city image and branding (Dwyer et al., 2005). Events and festivals are also being used to boost tourism to host cities and regions (Hodur \& Leistritz, 2006). Economic impact studies are being called upon by 
governments to determine whether public dollars should be used to invest in events to stimulate economic development (Dwyer, Mellor, Mistilis \& Mules, 2000; Dwyer, Forsyth, \& Spurr, 2005; Hodur et al., 2006; Robertson, Rogers \& Leask, 2009; Wood, 2005). These studies are often done by surveying festival attendees about where they come from, how they got to the event, and how much they spent during their visit (Burgan, 2000). Arts and music festivals, in particular, have shown to significantly contribute to local economy by bringing in patrons from around the region, nationally or internationally (Saayman \& Rossouw, 2010).

Even though these economic impact studies are conducted to assess the potential benefits and costs of economic development, there is a gap in the literature concerning a sustainable development perspective. Smith (2009) found that major events are often justified by host communities for their contribution to economic development, but often end up creating development that is unsustainable because the long term impact they leave compromises the ability of host communities to meet their own needs. This means that major events might bring short term economic benefits to communities, but their long term impacts may degrade host communities' self-sufficiency by making them compete for limited capital and resources. Smith also asserts that poor event design and management of major events that are initiated as long term re-development or city renewal can come at the cost of certain marginalized groups and create negative impacts on social networks, public health, transformation of space and displacement of people that disproportionately affects lower socio-economic classes and minorities. Planners of major events don't always consider long term impacts or whether long term impacts are 
equally distributed across social groups and networks. Major events may be "aimed at impressing outside interests, whilst placating residents via the provision of entertaining distractions ... a shift away from everyday social needs and cover up 'real' social problems" (Smith, p. 111). Similarly, Robertson, Rogers \& Leask (2009) found that while festivals are sometimes seen as one form of cultural production that can aid in the cultural development of the host location, there exists little guidance to aid festival directors to ensure a long-term and sustainable legacy of such festival-development projects.

Compared to economic impact studies, there is less research on the social, cultural, and political impacts of festivals (Arcodia \& Whitford, 2006; Robertson, Rogers \& Leask, 2009). A study by Arcodia and Whitford (2006) found that festivals can create social capital by encouraging civic engagement, social cohesiveness, community resources, public celebration and building community resources. Arcodia and Whitford argue that festivals should be utilized as a tool to develop social capital of communities, which they describe as "the processes between people which allow the establishment of a sense of cooperation, goodwill, reciprocity, belonging and fellowship" (p. 2). However, the development of social capital through festivals is only a potential outcome and is dependent on how well the event is managed (Arcodia \& Whitford). Without proper management, it is very easy for negative social impacts to be generated instead of positive ones. Some of these negative social impacts might include health risks, disruption of lifestyle, crime and vandalism (Tassiopoulos \& Johnson, 2009). 
Some researchers' economic impact studies of festivals are expanding their breadth to a total cost-benefit package that includes the social impacts of festivals. Dwyler, Mellor, Mistilis and Mules (2000) developed a framework that aimed to discern the intangible social costs and benefits in addition to economic valuation. Wood (2005) aimed to push the envelope even further to measure the intangible social constructs such as civic pride, quality of life and social belonging related to events in combination with economic impacts. Tassiopoulos and Johnson (2009) suggest the use of social impact assessments (SIA) to analyze, monitor and manage the intended and unintended social impacts of festivals and explain that an SIA "needs to be process-oriented to ensure that social issues are included in project design, planning and implementation, as well as ensuring that development is acceptable, equitable and sustainable" (p. 81). These studies are getting closer to understanding the whole impact of events in a more long term capacity.

There exists even less literature on the environmental impacts of events and festivals than their social and economic impacts. This gap in the literature is unusual since the bulk of sustainability initiatives of events and festivals are geared toward minimizing negative environmental impacts. This may evidence a lack of connection between the development of sustainable event management in the field and documentation of the topic in academic literature. Getz (2009) notes that the valuing of events has been obscured by an overemphasis of economic valuation which has left the social and cultural values of events with inadequate attention. In addition, the environmental impacts of events have mostly been ignored to the point where carbon 
footprints and energy costs of events are near absent from impact assessments (Getz).

The impacts of festivals on the environment accumulate through traveling and transport, use of accommodation and facilities, operation of necessary infrastructure, procurement of materials, generation of waste, and consumption of food, water and energy (David, 2009; Jones, 2010). Through these areas of impact, events and festivals can create enormous pressure on natural, human-made and ecosystem environments that strain their ability to cope within acceptable limits of change. Specifically, festivals can damage air quality, change geological conditions, pollute water, deplete natural resources and damage biodiversity of species (David).

Events as public good. An interesting theme in the literature is the discussion of events and festivals as a public good. Getz (2009) argues that although events and festivals can generate wealth and jobs, and boost the destination's image, tourism and economy, a much greater economic benefit is festivals' contribution to the public good. This kind of benefit can only be realized if the positive outcomes of the festival or event accrue to society as a whole, as is consistent with the definition of a public good. Getz continues to clarify that the public good benefit is only realistic if the festival asserts strong sustainability initiatives that align with public policy domains of inclusivity, health, cultural celebration and equity. While Getz's research shows that festivals can contribute to the public good of host communities, they can also detriment the public good of host communities. Smith (2009) explains that when public funds, space or facilities are diverted from public usage to a private event, this privatization of public goods pulls from available resources of host communities and can damage their 
wellbeing. A study by Foley and McPherson (2007) explored the concept of a festival's contribution of to the public good at Glasgow Winter Festival. The study aimed to determine whether the festival's duel economic objectives and community objectives could actually be realized. As much as the festival aimed to contribute to public good, the study found that the festival was more conducive to income generation and creating post-modern spectacle than meeting diverse cultural needs and improving the community's quality of life (Foley \& McPherson). The outcomes of this study show that it is more difficult than realized to create public good through events and festivals.

On the whole, literature that concerns sustainable event management points to an inconsistency between the objectives and outcomes for sustainability initiatives. This inconsistency is well demonstrated by Glasgow Winter Festival's discrepancy between the policy objectives set by the festival producers to create common good and the outcomes discovered once Foley and McPherson (2007) delved into the festival's actual impacts. Similarly, Smith (2009) noted that the multitude of positive impacts of events and festivals, such as social renewal, visibility and economic development, are potential impacts and require further research to determine whether they are actually realized. This means that while festival directors can have the best intentions to produce events that have positive impacts and outcomes, there is no certainty that their objectives will be realized. Therefore, there is a need for effective sustainable event management strategies to help festival directors ensure that events are actually generating positive impacts, and that these impacts create long term and sustainable legacies for host communities. 
Movement toward sustainable event management. Of the slim literature connecting events with sustainability, there are even fewer academic articles on existing strategies of sustainable events and sustainable event management. However, the following literature provides an overview to previous research and points to several important themes which may give guidance to music festival organizers as they work to improve sustainable event management of United States music festivals.

Of the literature found about sustainable event management, most uses the term 'event greening' and is primarily focused on addressing the environmental impacts of events and festivals. For example, when Laing and Frost (2009) explored activities happening in event greening of music festivals, common activities included operational issues of waste disposal, recycling, traffic, power, carbon offset schemes, water and resource procurement, and food acquisition. Additionally, Katzel (2007) proposes a sustainability rating system to standardize the practice of event greening and aims to maintain authenticity and integrity of sustainability events. It outlines fifteen components that should occur in all sustainable events. These include: 1) policies and management plans, 2) sustainable procurement of materials, 3) life cycle assessment of materials, 4) integrated waste management, 5) awareness raising and education, 6) water conservation, 7) energy conservation, 8) greenhouse gas compensation initiatives, 9) stakeholder and community involvement, 10) design and sustainable construction,11) responsible sponsorship, 12) efficient transportation, 13) biodiversity preservation and protection, 14) urban renewal, and 15) leaving a positive legacy (p.32). This list is comprehensive and provides a good example of sustainability initiatives that may be considered by music 
festivals organizers. However, the implementation of such is not common practice. Getz (2009) notes that one basic standard that has gained common acceptance is for events to be "clean and green" (p. 68) which generally translates to a simple reduce, reuse and recycle program.

An internationally commissioned paper by the United Nations Music and Environment Initiative (UNM\&E) aimed to provide a global overview of the music industry's effort to address environmental sustainability (Jones \& Scanlon, 2010). The document identified three important findings that can be seen as barriers to wide scale uptake of greening within the music industry, which includes music festivals. Firstly, insufficient know-how, limited financial investment and limited availability of skilled staff are an immediate challenge to greening. Secondly, a lack of regulation throughout the music industry to encourage greening has given way to the emergence of independent adopters whose efforts are fragmented rather than synergetic. Lastly, the greatest problems were seen to be transport, energy consumption and waste generation. Based on these findings, the UN M\&E aims to assist in reducing the skills and knowledge gap of greening issues between nations, and build networks and campaigns to address greening opportunities (Jones \& Scanlon). This is an amazing effort on behalf of the international body and will hopefully encourage a stronger base level standard throughout the music industry and all of music festivals. However, at an international scale, the reach of this body can only extend so far. There still remains a need to better understand the challenges and successes of United States music festival organizers specifically so that 
organizers can have strategies to address their specific needs in sustainable event management.

The need to bring sustainable and responsible events to greater prominence is recognized in other literature (Getz, 2009; Katzel, 2007). Getz (2009) asserts that to do so, the events industry will require institutionalization of a new paradigm, one that values the worth and impacts of events through a triple bottom line approach. Sustainable events fulfill important social, economic and environmental roles, and Getz calls for public policy to assist in the development of sustainable and responsible events. Institutionalization of policy will occur when the sustainability paradigm is better adopted in public consciousness. Getz further asserts the need for non-academic public champions to sell the paradigm shift to the public and describes the need for institutions and strategic alliances to assist in the adoption of this paradigm.

Existing strategies of sustainable events. There are few articles in the literature that identify existing strategies of sustainable events. On the whole, the literature points toward management of stakeholders and community networks as effective strategies. Stakeholder engagement and participation contributes to festival viability and the success of sustainability initiatives (Anderson \& Getz, 2008; Laing \& Frost, 2009). Anderson and Getz (2008) found that by maintaining the support of committed stakeholders with the community, media and suppliers, festival organizers are better able to sustain long-term viability of festivals. Collaborative alliances and cooperation of stakeholders including sponsors, community groups, relevant government agencies and departments, venue and land managers, artists, staff and attendees can contribute to positive outcomes of 
sustainability initiatives of music festivals (Laing \& Frost). These stakeholder collaborations increase communication, minimize conflict, build a sense of identity and provide common goals. Robertson, Rogers and Leask (2009) found that festival directors and managers play critical roles in managing these important stakeholder needs and relationships. Similarly, Arcodia and Whitford (2006) suggest that the difference between festivals' generating positive or negative social impacts are the management strategies of festival directors. Festival directors and organizers who facilitate community consultation and collaboration throughout the course of the event as well as before and after the event see much more positive outcomes (Arcodia \& Whitford). Additionally, a synthesis of literature by Robertson et al. found that understanding the networks and relationships that exist within the festival, community and event industry is an important strategy for festival sustainability. If festival organizers are able to understand linkages and have the ability to manage networks, they can build better relationships, sustain support and inspire confidence with festival stakeholders (Robertson et al.).

Concerning sustainable event management strategies of music festivals, a study by Brooks, O'Halloran and Magnin (2007) provided a unique perspective to the field. The study examined measures music festivals could take to strategically move toward sustainability and found five key leverage points to encourage this process: the music festival organizer as a middle man between important stakeholders, the formation of strategic alliances between festival organizers to push industry direction, the regulatory and financial support of political bodies to facilitate sustainable development of festivals, 
and festival driven messaging to promote ideas through the broader community (Brooks et al.). To conclude the study, Brooks et al. created a guide book for music festivals that uses the Natural Step Framework to assist organizers to strategically design and plan for sustainable event management of music festivals. The Natural Step Framework will be further discussed in the next section of this chapter. Both the study and guide book provide a science and systems-based sustainability framing and strategic long term planning for sustainable event management. This approach is unique because it brings together sustainability theory, systems theory and important ecological principles to the field of event management. In contrast, the bulk of academic literature that converge events with sustainability derives primarily from the event management field and then aims to incorporate sustainability ideas. The incorporation of sustainable development principles to other disciplines is critical to actually achieving sustainability in the field, and this study has led the way in doing just this.

This review of literature has provided an overview of existing research on the impacts of events, movement toward sustainable event management and existing strategies of sustainable events. It has shown that there is a gap in the events literature missing a sustainability perspective. It has also shown that even with good objectives, events can create harmful impacts and be unsustainable without good design, management and a long-term perspective. Writers agree that a need exists to bring sustainable events to greater prominence, and existing strategies point to stakeholder and community network management. The Brooks et al. (2007) study was pioneering and is a valuable contribution research in sustainable event management. However, neither the 
guide book nor the recommendation of strategic sustainable event design and planning is widely used by United States music festivals. This not only shows a discrepancy between the academic research and implementation in the field of event management, but also exposes a need for further research. There is a need to understand the particular challenges and success factors of United States music festival organizers to better determine specific strategies that will help music festival organizers move their festivals toward sustainability.

\section{Organizational Change for Sustainability}

The last section of the literature review is on organizational change for sustainability. Music festivals are organizations, and much of the change that needs to take place to move toward sustainability is organizational. Organizations of all forms are primary contributors to climate change, resource depletion, industrial pollution, food insecurity, social injustices, and degradation of human health and wellness among other issues (Lubin \& Esty, 2010; Pfeffer, 2010). Because so much change needs to happen to move organizations toward sustainability, research is being done to shine light on the challenging processes of organizational change for sustainability. The field of organizational change studies reveals lessons in how music festivals can create changes to best integrate sustainability into event management, production and operations.

The nature of organizations and change. It is important to understand how organizations function in order to understand how to change them. The complexity and irrationality of organizations is discussed throughout the literature of organizational studies. Organizations are political, unpredictable and rarely behave as they are expected 
to (Bolman \& Deal, 2008). Often organizations are set in macro-industries or institutions that have deeply embedded assumptions which can be very influential on organizational culture (Senge, 1990). This means that it is not uncommon for organizations to be driven by their assumptions rather than facts or reasoning. Because organizations are parts of complex systems that function with given inertias, changes are often times only surface level (Senge). Real and lasting organizational change must be deep and systemic (Bolman \& Deal). For all these reasons, organizational change has long been viewed by scholars as a difficult undertaking fraught with many impediments.

The classic organizational change literature is full of numerous models, methods, case studies and strategies that have been compiled to provide guidance for agents interested in changing organizations. Even so, change strategies often fail and the same mistakes are made time and time again (Bolman \& Deal, 2008). Kotter and Cohen (2002) designed an eight step model that pinpoints the most important elements of organizational change which are:

1) Creating a sense of urgency

2) Establishing a guiding team

3) Designing an uplifting vision and strategy

4) Communicating this vision and strategy with words, deeds and symbols

5) Removing obstacles to empower people to move forward

6) Producing symbols of progress through short term victories

7) Sticking with the process when it gets tough

8) Shaping a new culture to support new ways (p. 3) 
Kotter and Cohen's (2002) change model has been widely influential in organizational studies. They argue that too many change strategies fail because they are more focused on reason and structure than on creativity and human needs and emotions. Bolman and Deal (2008) add that change strategies designed and implemented from the top often fail because decision-makers don't understand the organizational environment well enough to conceive of the consequences of different actions. They suggest that a multi-frame analysis structured to individual organizations will achieve more positive outcomes in organizational change. Bolman and Deal define four frames that can be used to understand organizations: the structural realignment frame views organizations as factories, the political bargaining frame views organizations as jungles, the human resources frame views organizations as families, and the symbolic rituals frame views organizations as temples (Bolman \& Deal). Each of these four frames provides a different way of viewing an organization and its needs. Additionally, each of these four frames provides a different approach to working through diverse organizational issues. Reframing organizational change issues through each these multiple lenses is effective because it allows for the use of different tools to maneuver the unpredictable nature of organizations.

Changing for sustainability. The sustainability movement has been likened to the Intellectual Technology (IT) and Quality Movements in which a change in the scenery ultimately affects the structure, operations, views and business models of literally all organizations (Lubin \& Esty, 2010). For instance, any organizations that existed during and after the IT movement were forced to integrate IT systems into all aspects of 
organization. Those organizations that refused to make the necessary transition to intellectual technology ran the risk of collapsing as the movement passed them by. This comparison suggests that it is imperative for organizations to make changes for sustainability or face great risks. Of the literature found that contributes to the field of organizational change for sustainability, sustainability and organizational theory come together to create a framing for the processes, practices, and strategies of organizational sustainability transformation.

Some literature brings sustainability theory and principles to the study of organizational change. Capra (2002) brings an ecological perspective and theory of living systems to organizational change studies and suggests that the best way to change organizations is to first understand how change happens in natural systems. Then, the processes of organizational change can be designed to "mirror life's adaptability, diversity and creativity" (Capra, p. 100). Organizational learning is a theory that studies that adaptive capacity of organizations to sense changes it their environment and learn according to those changes (Senge, 1990). Senge describes the concept of organizational learning as a method in which:

people continually expand their capacity to create the results they truly desire, where new and expansive patterns of thinking are nurtured, where collective aspiration is set free, and where people are continually learning to see the whole together. (p.3)

Organizational learning capabilities are developed through personal mastery, challenging mental modes, building a shared vision, team learning and systems thinking (Senge, 
1990). Systems theory is an important conceptual theory to sustainability thought and was introduced in the first section of this chapter. Similarly, Sharp (2002) stresses the importance of recognizing the irrationality of organizations in order to reframe their rigid structural models as more organic and adaptive. Organizations that are structured organically can more easily shift priorities and resources with the changing environment (Sharp). Conceiving of organizations with sustainability principles is important to making lasting and effective changes to make organizations more sustainable.

Models and frameworks have been developed to help change leaders take on the necessary changes for organizational sustainability transformation. For example, one popular sustainability model is the Natural Step Framework. It provides a science-based framework that helps organizations strategically plan and make decisions for the transition of sustainability (The Natural Step, 2009). Of the articles reviewed in organizational change for sustainability, the most obvious theme is the emphasis of change as a process. Organizational change for sustainability cannot be implemented with one or two initiatives, but must rather be developed and grown through time. To better understand the stages of organizational change within a sustainability framework, several articles were synthesized. The stages of organizational change for sustainability framing are further discussed below.

A shared vision. The organizational change for sustainability process first requires a shared vision (Luban \& Esty, 2010; Senge, 1990; Sharp, 2002; The Natural Step, 2009). This first step is critical because many organizations begin launching sustainability initiatives without any clear direction of their destination (Luban \& Esty; 
Senge, 2008; Sharp). Organizations not only need a clear vision of where they are going but an understanding of how healthier social and environmental systems are integral to organization's sense of purpose and strategy (Senge, 2008). The Natural Step (2009) encourages back-casting, the method of deciding what it is wanted in the future and determining what we have to do in the present to get there.

Create goals and indicators. The next stage is to create goals and indicators to reach the organization's shared vision. This stage involves assessing points of unsustainability in the organization's current state and drafting an agenda to address those points with sustainable initiatives. Senge (2008) identifies this early stage as one that most organizations are able to reach in the sustainability transformation and describes it as identifying and reducing unsustainability while increasing sustainability. In this stage, The Natural Step (2009) suggests creating a baseline analysis of inventory assets, a sustainability impact assessment and a stakeholder evaluation. From this analysis, long term strategic goals should be created.

For all kinds of organizations sustainability accounting and reporting has shown to help organize thoughts and actions as well as lay a road map for implementing these initiatives (Grey, Walters, Bebbington, \& Thompson, 1995). For business organizations, in particular, the process of creating environmental and social accounts has shown to be far more effective at creating change than drafting an environmental agenda or a corporate written commitment (Grey et al., 1995). The concept and terminology of accounting holds strong and symbolic status of corporate value and communicates corporate language (Grey et al., 1995). For non-corporate and corporate organizations 
alike, the process of identifying performance indicators has shown to be an extremely effective step in the organizational sustainability process (the Natural Step, 2009).

Changes in basic operations. The next state in organizational transformation is to make changes in basic operations to address waste reduction, energy efficiency and water improvements and other key starting points (Lubin \& Esty, 2010; Senge, 2008; The Natural Step; 2009). Senge (2008) calls the cost savings made in these basic changes the "low-hanging fruit" of sustainability transformation and points out that this stage is where many companies got stuck during the Quality Movement. Sustainability leaders are able to move past this point of operational changes, and are the ones who achieve greater organizational sustainability change (Sharp, 2002). This is the difference between individual projects and systemic transformation of sustainability (Sharp).

Redesign organizational processes and systems. Redesigning selected processes, functions and systems to improve organizational performance is the next stage in the organizational sustainability transformation (Lubin \& Esty, 2010; Senge, 2008). This stage can described as "progressing from doing old things in new ways to doing new things in new ways" (Lubin \& Esty, 2010, p. 47). Senge (2008) calls this stage one of redesign and reconstruction, and notes that fewer organizations have crossed the boundaries to build healthier supply chains and new tracking systems (Senge).

Innovation. The next stage of organizational transformation is to integrate innovative approaches into organizational core strategies (Lubin \& Esty, 2010; Senge, 2008). Sustainability innovations become part of new revenue and growth for organizations (Lubin \& Esty). In this stage, organizations recreate value with new 
products or technology design (Senge). Senge further emphasizes the importance of this stage because it is a transition from problem solving to creating.

Restructure and rebuild business models. Redefining strategy for competitive advantage through restructuring and rebuilding business models is the last stage of organizational sustainability transformation (Lubin \& Esty, 2010; Senge, 2008). Organizations use sustainability as a source for differentiation for brand, employee engagement and redefinition of strategy (Lubin \& Esty). At this point, the organization as carved out sustainability is an integrated strategy and uses it for business opportunities (Senge). Finally, sustainability is fully aligned with the organization's core values, purpose and mission (Senge). While these stages are important to framing organizational change for sustainability, another important consideration is the change that must undergo in the organizational culture.

Organizational culture change and sustainability. Although changing culture may be difficult, many articles suggest that it is still an integral component of both the necessary sustainability transformation and organizational change for sustainability (Georg \& Fussel, 2000; Mitchell, Curtis, \& Davidson, 2008; Senge, 1990; Sharp, 2002). When Harris and Crane (2002) investigated "green" organizational culture change they found that it is extremely difficult to achieve. The study showed that sustainability ideas and beliefs confront and filter through an organization's existing cultural assumptions and ideas rather than birth a new cultural transformation (Harris \& Crane). Similarly, Senge (1990) emphasizes the importance of challenging conventional assumptions and mental modes in making change for sustainability. The constructivist approach to 
organizational culture change for sustainability involves making "greening" an emergent process in which organizational members reconstruct their identities and collective perceptions by making sense of sustainability and greening processes (Georg \& Fussel, 2000). Georg and Fussel argue that an environmental commitment cannot be assumed, but must rather emerge as people reframe their emotions, interpretations and actions as they engage with one another and the greening process. They found that through this process, the organizational members and the organization itself were able to develop new ideas and beliefs about sustainability (Georg \& Fussel, 2000). These pieces of research demonstrate the critical role of sustainability education to changing organizational culture.

Working to change organizational culture is an imperative component to making sustainability change within the organization substantive. A synthesis of literature and case studies by Mitchell et al. (2008) found that when sustainability reporting is practiced as a collaborative learning process and capacity-building opportunity, organizations increased their potential for realizing triple bottom line sustainability outcomes. Sustainability accounting and reporting has been criticized for not making the necessary changes to create real sustainability transformation. Mitchell et al. found that much sustainability reporting often has more to do with "public impression management" than creating any substantive changes (Mitchell et al., p. 68). Similarly, Reily (2009) found that firms tend to report only what makes their organizations appear more favorable to improve reputation or avoid public criticism. To make organizational sustainability changes truly effective, wide participation of stakeholders should engage in regular 
dialogue, reflection and learning (Harris \& Crane, 2002). They should together identify sustainability indicators unique to their organization, actively discuss embedded organizational assumptions and brainstorm solutions for the organization's unsustainability (Harris \& Crane). This further demonstrates how sustainability learning is a critical element to sustainability framing and creating effective organizational transformation for sustainability.

The ideas around organizational change for sustainability and sustainability framing are applicable to understanding the nature of music festival organizations and how sustainability can be integrated throughout the event planning process. As music festivals are organizations, the lessons drawn from this literature review of organizational studies can be borrowed and applied to organizational change of sustainable event management.

\section{Conclusion}

When envisioned, designed and managed for sustainability, music festivals have much to contribute to the transition of sustainability. For sustainable event management to become common practice and this greater potential to be realized, music festival organizers are in need of strategies to help them improve sustainable event management. This chapter reviewed existing literature on important concepts, previous research and lessons borrowed from another discipline to create a strong background for this study. This overview of information is important to creating a foundational understanding around sustainable event management that will support the rest of this thesis. 


\section{Methodology}

This chapter provides an overview of the methods of this research. First, the purpose of the study and research questions are reviewed. Then the research design is presented. This section then gives an overview of the study participants, data collection, and data analysis. The chapter closes with a brief discussion of the validity and limitations of the study.

\section{Research Questions}

This study looks at the issues surrounding the improvement of sustainable event management of music festivals in the United States. The purpose of the study is to more succinctly understand sustainable event management through music festival organizers' experiences and perspectives. With an understanding of the barriers and success factors that event organizers face moving their music festivals toward sustainability, strategies can be identified that that will improve sustainable event management. This study examines the following research questions: What are the barriers and success factors associated with sustainable event management of music festivals? What, specifically, do music festival organizers need to improve the sustainable event management of their festivals?

\section{Research Design}

The research for this study was designed in two parts that are characterized by the use of two primary data collection instruments. The first part used a cross-sectional survey to collect both quantitative and qualitative data. The second part used semistructured interviews to expand upon the survey data with an additional qualitative 
analysis. This research design used a mixed quantitative-qualitative model that combines triangulation and explanatory mixed method designs (Gay, Mills \& Airasian, 2009). The first part of the study used a triangulation method design where both quantitative and qualitative data were collected concurrently and are equally weighted in analysis (Gay et al.). This kind of methodology is beneficial because the strengths of the qualitative data offset the weaknesses of the quantitative data and the strengths of the quantitative data offset the weaknesses of the qualitative data (Gay et al.). The second part of the study used an explanatory method design. This is where a qualitative analysis and interpretation are used to bring explanation and elaboration to the results of previously collected data (Gay et al.). The use of these mixed methods brings a comprehensive and fully integrated approach to the study's research design.

This research design can also be considered both intrinsic and instrumental. Intrinsic research aims to better understand the experiences of the study participants, while instrumental research aims to generate insight into the theoretical underpinnings of a greater issue (Hancock \& Algonzzine, 2006). Specifically, this research was intrinsic because it aimed to look at the particular experiences and perspectives of the study subjects concerning sustainable event management to identify the challenges and success factors they encounter in their work. This research was also instrumental because it aimed to generate an understanding of the barriers the United States music festival community faces in its transition to improved sustainability. Finally, this research design was informed from the researcher's existing knowledge base and experiences surrounding the convergence of music festivals with sustainability. 
Data collection. For this study, data was collected with the use of two primary instruments, a cross-sectional survey and partly-structured interviews. Cross-sectional surveys are stand alone surveys that gather wide-ranging data from a sample at a single point in time (Gay, Mills \& Airasian, 2009). The researcher chose to use a crosssectional survey because it is an effective way to gather a broad and general understanding of the current attitudes, beliefs and opinions of a population relatively quickly (Gay et al.). From this snapshot of event organizers' perspectives and experiences concerning sustainable event management, partially-structured interviews were used to complement and expand on the survey data. Interviews were chosen because they are an effective, in-depth data collection instrument that more fully explores subjects' stories, perceptions and concerns (Gay et al.). Interviews that are only partially structured use predetermined and open-ended questions as prompts but allow the conversation to follow the interviewee's guide to unveil his or her experiences and perceptions (Gay et al.).

Survey. The survey consisted of 30 questions that were formatted in four different styles (See Appendix A). These styles included multiple choice, number-scaled, Likert-scaled and open response. First, the subjects were asked to provide demographic background information about the festivals they represented including number of attendees, genre, and kind of production. The participants were then asked to rate the importance of triple bottom line sustainability to their festival and to rate their festival's engagement with triple bottom line sustainability. Next, the participants were asked about their professional experiences in the event industry and working with sustainability. 
The participants were then asked to rate the effectiveness of different factors that might improve the sustainable event management of their festivals. The last set of questions was open response and asked the participants to describe their challenges and needs regarding sustainable event management based on their experiences and perspectives. The final question asked the subjects to rate the current state of triple bottom line sustainability of the United States music festival community. For clarity, the terms 'sustainable event management' and 'triple bottom line sustainability' were defined at the beginning of the survey. Before the survey was distributed, it was pilot tested by three of the researcher's academic peers.

The surveys were constructed with the online survey tool, Surveymonkey, and distributed via e-mail to 60 selected participants. E-mails were composed of a cover letter of informed consent with a link to the survey in the body of the e-mail. The cover letter of informed consent communicated the purpose and overview of the survey, risk and confidentiality details, and a commitment to share the study results when completed. The researcher did not have the names or contact information of all 60 selected participants because the participants were chosen based on the music festivals with which they are associated. This is further discussed in the research participants section. If the participant names and contact information were available, the researcher sent the e-mails directly to the participants. If this information was not available, emails were sent to the most available e-mail address associated with the festival. In these cases, a note was written at the beginning of the e-mail asking the recipient to forward the e-mail to the individual most responsible for sustainability coordination and decision-making for the 
festival. The researcher used both phone and e-mail to connect with the participants whenever possible. Follow up e-mails were sent three weeks after the initial distribution to encourage participants to return the surveys. Eight weeks after the initial distribution, a second round of follow up emails was sent in an effort to collect the remaining surveys.

Interviews. Interview participants were contacted via phone, e-mail, in-person, or a combination of the previous. An email was sent to the participants that included a thank-you for their participation in the survey, brief overview of the interview, PDF file of the letter of informed consent, and a request to discuss sustainable event management further in an interview. Three of the five interviews were held via phone, and two were held in person. The interviews were recorded partly by a digital audio recorder and partly by notes. The audio pieces were transcribed by the researcher. The length of each interview ranged from 40 minutes to 90 minutes. For the interview participants, confidentiality was addressed with the use of pseudonyms in the transcripts and final thesis paper.

Themes were derived from the survey data analysis and used to guide the construction of nine semi-structured interview questions (See Appendix B). With these pre-determined questions, each interview was molded to best leverage the participants' unique perspectives and experiences. Interview participants were asked to talk about their perceptions of sustainable event management and the challenges and achievements of their festivals. They were also asked questions about music festival diversity, economic viability, leadership and the music festival community as a whole. The 
interviews were semi-structured because the researcher allowed the content, stories and feel of each conversation to flow naturally.

Research participants. When selecting participants for the survey portion of this study, emphasis was on ensuring that the study sample adequately represented the diversity of music festivals in the United States. A thorough understanding of the whole music festival population and extensive reach to all the population's diverse parts were pertinent to the validity of the study. The researcher collected a list of music festivals that take place throughout the United States and differ in region, musical genre, kind of producer, location in urban versus rural space, and scale using attendance as an indicator. As there is no single documented list of United States music festivals, the researcher used a variety of different sources to gain a sufficient understanding of the population. The following live music and festival databases and concert reviewers were used to find and categorize a list of music festivals: MetroWize (n.d.), JamBase (n.d.), FestivalFinder (n.d.), Festivals.com (n.d.), Wikipedia (n.d.), and A Greener Festival, Ltd. (n.d.). In addition, The $10^{\text {th }}$ Annual Festival Guide of Relix Magazine (Greenhaus, 2010) and the book Music Festivals in America (Rabin \& Elke, 1990) were used in combination with the previous databases. Upwards of fifteen hundred music festivals were reviewed from these sources. Finally, the researcher selected 60 diverse music festivals as a sample to represent the greater United States music festival population. These 60 music festivals are equally distributed across region, musical genre, kind of producer, location in urban versus rural space, and scale using attendance as an indicator. The researcher also aimed 
to include a balance of well-known and less-known music festivals. Figure 1 illustrates this diversity in musical genres.

Figure 1. Musical genre of festivals represented in study.

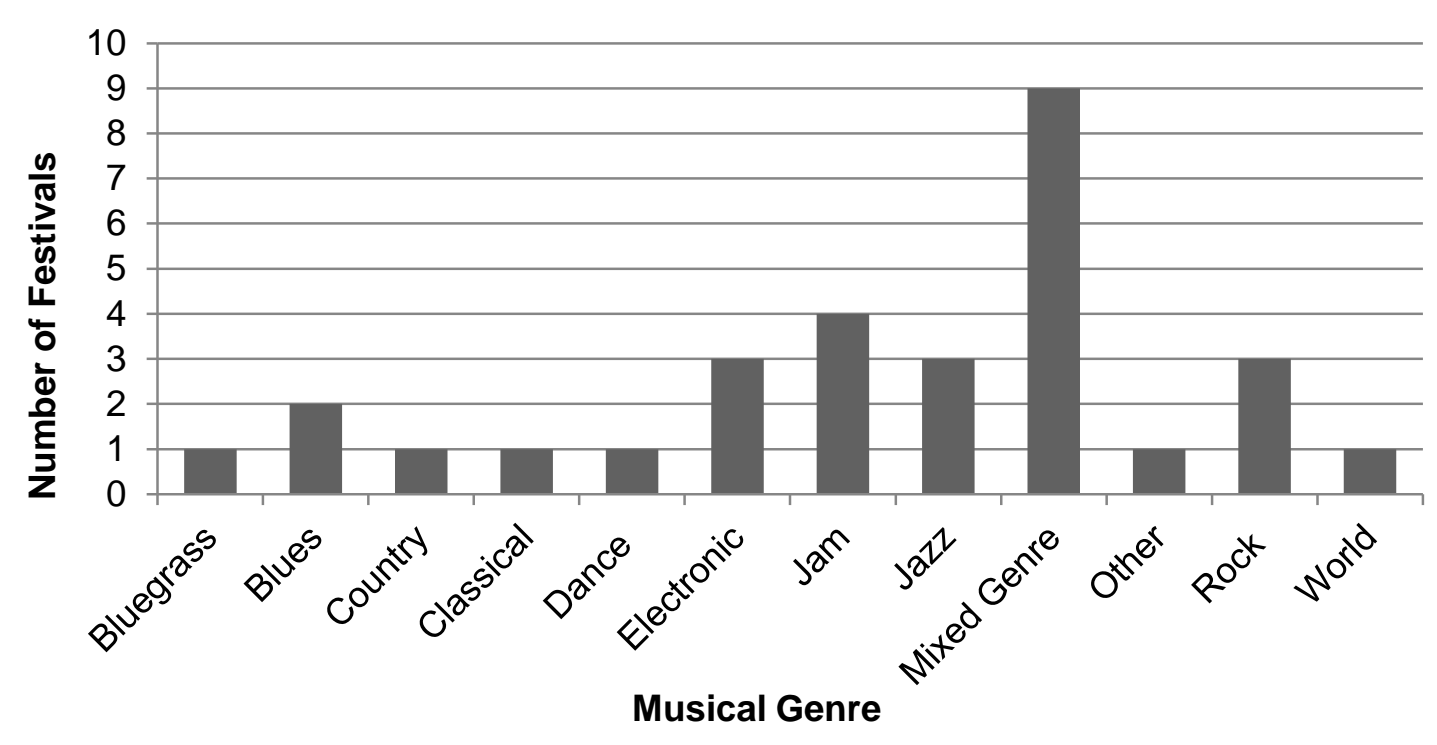

This graph illustrates the diversity of festivals represented in the study by musical genre.

The festivals represented in the study provide a relatively equal representation across scale and in different kinds of production. The festivals ranged from hosting fewer than 5,000 attendees to more than 160,000 attendees. The festivals are produced by production companies or corporations, independent entities, non-profit organizations, collaborations amongst the above or other unnamed kinds of production. These results are important because diversity in these variables give validity to the study results by providing balance in perspective. Figures 2 illustrates the diversity in scale, and Figure 3 illustrates the diversity in kind of production. 
Figure 2. Attendees of festivals represented in study.

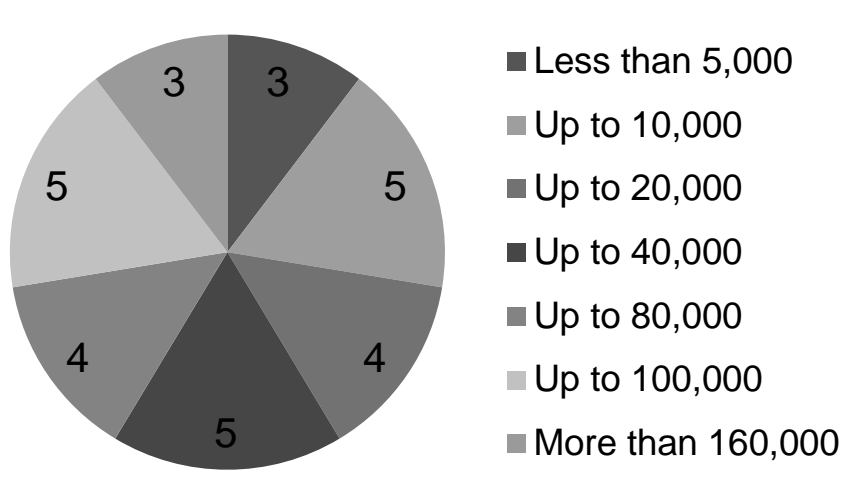

This graph illustrates the diversity of festivals represented in the study by scale.

The categories are numbers of attendees. The data labels in the graph indicate the number of festivals represented in each category. 
Figure 3. Kinds of festival production represented in study.

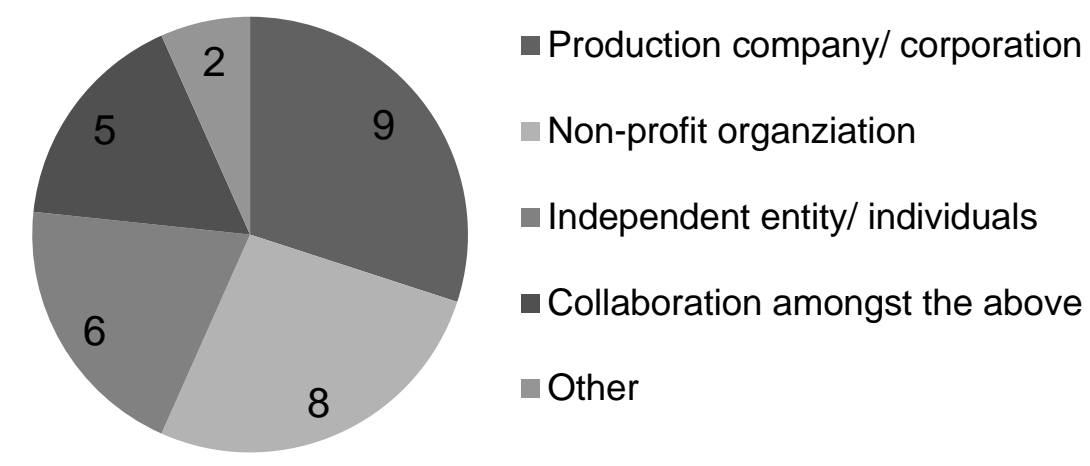

This graph illustrates the diversity of festivals represented in the study by producer. The data labels in the graph indicate the number of festivals represented in each category.

From the 60 music festivals represented in the study, the researcher worked to identify a representative subject from each festival to participate in the survey portion of data collection. The researcher contacted the festival promoter, owner, production company, or affiliated producing organization to identify the individual most responsible for the festival's sustainability coordination and decision-making. The subject selection was based only on titles and roles within the festival organizations and referrals from the individuals with whom the researcher made contact. Of the 60 surveys distributed, 30 were completed sufficiently to be used in data analysis. While the identification of the survey participants is confidential, Table 1 provides a list of the music festivals represented in the survey. 
Table 1

Festivals Represented in Survey

\begin{tabular}{|c|c|c|}
\hline Name & Location & Attendees \\
\hline Bayou Boogaloo & New Orleans, LA & 24,000 \\
\hline Bumbershoot Festival: Seattle's Music and Arts Festival & Seattle, WA & 125,000 \\
\hline Bonnaroo Music and Arts Festival & Manchester, TN & 85,000 \\
\hline Camp Bisco & Mariaville, NY & 15,000 \\
\hline Country Stampede & Manhattan, KS & 160,000 \\
\hline Desert Rocks Music Festival & Moab, UT & 4,000 \\
\hline Fingerlakes Grassroots Festival of Music and Dance & Trumansburg, NY & 10,000 \\
\hline Floydfest & Floyd, VA & 14,000 \\
\hline Freihofer's Jazz Festival & Saratoga Springs, NY & 12,000 \\
\hline Gathering of the Vibes Music and Arts Festival & Bridgeport, CT & 22,000 \\
\hline George Wein's Newport Folk Festival & Newport, RI & 17,000 \\
\hline Harmony Festival & Santa Rosa, CA & 35,000 \\
\hline Lightning in a Bottle & Irvine, $\mathrm{CA}$ & 6,000 \\
\hline Lionel Hampton International Jazz Festival & Moscow, ID & 10,000 \\
\hline Lollaopalooza & Chicago, IL & 80,000 \\
\hline Memphis Music and Heritage Festival & Memphis, TN & 40,000 \\
\hline Mendocino Music Festival & Mendocino, CA & 6,000 \\
\hline New Orleans Jazz and Heritage Festival & New Orleans, LA & 350,000 \\
\hline Petaluma River Revival Festival & Santa Rosa, CA & 6,000 \\
\hline The Power to the Peaceful Festival & San Francisco, CA & 70,000 \\
\hline Riverbend Festival & Chattanooga, TN & 650,000 \\
\hline
\end{tabular}


San Francisco LovEvolution

Sasquatch! Music Festival

Shakori Hills Grassroots Festival

South by Southwest Music and Media Conference

Summercamp Music Festival

Targhee Music Festival

Telluride Bluegrass Festival

Telluride Jazz Celebration

Waterfront Blues Festival
San Francisco, CA

George, WA

Silk Hope, NC

Austin, TX

Chillicothe, IL

Alta, Wyoming

Telluride, CO

Telluride, CO

Portland, OR
100,000

80,000

100,000

10,000

4,000

12,000

4,000

90,000

While the identification of the study participants is confidential, background information of the participants was gathered. By description, the study participants are the individuals who are most responsible for sustainability coordination and decision making of music festivals. The titles of these individuals include Production Manager, Executive Director, Operations Manager, Sustainability and Outreach Coordinator and many more. The study participants are mid-level to top-level management event professionals who have significant event industry experience. Ninety-seven percent of all participants have five or more years' event industry experience, and 48 percent of all participants have ten or more years' event industry experience. Comparatively, the participants' experience working in sustainability, including work that uses sustainability frame of mind, is much more varied. Participants' experience ranges widely from no experience at all to more than ten years' experience. If the participants have received sustainability education and training, it has come from primarily two sources. Fifty-five 
SUSTAINABLE EVENT MANAGEMENT

percent of participants have gained sustainability education by reading books, journals and publications, and 52 percent of all participants have gained sustainability education and training through on the job or professional experience. Figure 4 illustrates the sources from which the participants have received their education in sustainability.

Figure 4. Sustainability education and training of study participants.

I have a higher education degree in a
sustainability-related field
lam part of a sustainability-related
organization or professional association
I have completed a workshop or class
I have read books, journals or publications
I have gained on the job or professional
experience


Of the survey participants, the researcher selected five to participate in the interview portion of the data collection. The five interview participants were selected based on four criteria. First, they were selected for their comparative differences to one another working with festivals of varying region, musical genre, kind of production, and location to urban versus rural space and size. Second, each interview participant who was selected has comparatively robust experience in his or her work. Third, the selected participants provided open response comments in the survey that represented basic themes exhibited by the whole of survey data. The final criterion was a willingness to participate in the interview. The interview participants are listed in Table 2. The names of the participants have been changed to safeguard their identities.

Table 2

Participants in Interview

\begin{tabular}{lllc}
\hline Name & Festival Represented & Location & Attendees \\
\hline Terry & Bonnaroo Music and Arts Festival & Manchester, TN & 85,000 \\
Chris & Gathering of the Vibes Music and Arts Festival & Bridgeport, CT & 22,000 \\
Oddie & Lionel Hampton International Jazz Festival & Moscow, ID & 10,000 \\
Kerrie & Petaluma River Revival Festival & Santa Rosa, CA & 6,000 \\
Morgan & South by Southwest Conference and Festival & Austin, TX & 100,000 \\
\hline
\end{tabular}


Data Analysis. After the surveys were distributed and reminders sent, 37 of the 60 surveys were collected. Of the 37 surveys collected, 30 were completed sufficiently for data analysis. The surveys had four different kinds of questions, and each kind was analyzed differently. The multiple choice, number-scaled and Likert-scaled questions provided quantitative data. For each multiple choice question, the responses were totaled, assigned percentages of the whole and graphed for comparison. The numberscaled questions were each totaled and averaged. The Likert-scaled questions were analyzed through value-coding. A numerical value code was systematically assigned to each of the five Likert options: extremely effective, somewhat effective, effective, neutral and ineffective. This process was done twice, each with a different value set to ensure conclusive results. The value sets were $(3,2,1,0,-1)$ and $(4,3,2,1,0)$. For each question, the total responses of each option were multiplied by the assigned value and summed together. This gave each Likert-scaled question a total numerical value. The total values of each were then graphed for comparison. From the quantitative data of the multiple choice questions, number-scaled questions and Likert-scaled questions, themes were extracted and set aside to be compared with those from the rest of the study's data.

The qualitative data of the surveys, which consisted of various open response questions, were coded, organized into themes and quantified. Similar to the value-coding process, qualitative coding is the process of categorically marking units of text, such as words or phrases, with codes which are then ordered into categories or themes (Gay, Mills \& Airasian, 2009). The number of responses in each theme was totaled, and themes were assigned numerical data for comparison of prevalence. The resulting 
themes and ambiguities from this analysis were used to guide the content of the interview questions.

The interview data was collected in the form of transcribed text. This transcribed text was also qualitatively coded for themes. Unlike the survey data coding process, the themes pulled from the interview data were broader and used for corroboration and comparison to the survey data. Much of the aim of the interviews was to provide explanation and expansion of the themes extracted from the survey data. Therefore, the interview data was also reviewed for trends and interpreted by the researcher. The goal of interpreting data is to find meaning, and is based on finding connections, characteristics, categories and patterns distinct from others (Gray, Mills \& Airasian, 2009). Successful interpretation requires identifying and abstracting detail and complexity in data and depends on the perspective and interpretive abilities of the researcher (Gray et al.). To execute good interpretation of the interview data, the researcher aimed to maintain a perspective based in sustainability theory, presented in the Chapter 2 literature review of this thesis.

Validity. The study sample and research design are strong and contribute to the validity of this study. However, there are certain threats to validity that became apparent in the data collection process. The digital recorder the researcher used to record the phone interviews was not fully effective, and in a few occasions made some parts of the digital recording undecipherable. In these cases, the researcher's notes supplemented the poor recordings. When interviewing in person, the researcher's audio recorder occasionally stopped and restarted leaving holes in the recording that were also filled by 
the researcher's notes. To amend poor and incomplete recordings, the researcher verified interview material with follow-up e-mails to the interview participants.

Limitations. There are a few limitations to this study. First, the participants may not have fully understood some of the language used in the survey. Feedback from a few participants showed that the term "triple bottom line" was not commonly understood. Considering that the term was defined at the beginning of the survey, this feedback shows that participants may have still felt uncomfortable with unfamiliar concepts on the survey. Second, the Likert-scale exhibited weaknesses as a data collection instrument. The leading question for the Likert-scale was posed hypothetically, "What factors would be most effective ..." This format of question is very different that asking, "What factors have been most effective ..." It is possible that the answers are more ideological and less concrete than the survey aimed to collect. Another limitation to the Likert-scale data that stemmed from a hypothetically formed question is that participants based their responses from different baselines. For example, the factor of 'improved top management support' would be ranked much more effective by those festival organizers who do not have supportive top management forces. On the other hand, those festival organizers who already have very supportive top management would rank the factor much less effective. Had these participants been asked, "What factors have been most effective," the results may have been more definitive of actual factors that have proven to be successful, rather than hypothetical success factors. 


\section{Conclusion}

The methods described in this chapter were employed to gain an understanding of event organizers' perspectives and experiences of moving music festivals toward sustainability. The methods were specifically aimed to identify the barriers and success factors associated with sustainable event management of music festivals. Only with a clear understanding of these barriers and success factors can strategies be devised to help event organizers improve the sustainable event management of their music festivals. Working to integrate sustainability into the project planning process of event management is no easy feat. If event organizers have clear strategies aid them in this effort, sustainable event management can more easily be adopted and expanded as common practice throughout the United States music festival community. The next chapter will present the results that derived from the study methods. 


\section{Chapter 4: Results}

This study aims to understand the challenges and success factors that event organizers encounter in sustainable event management and seeks to identify strategies that will help organizers improve the sustainable event management of their music festivals. Through data collection and analysis, results were derived to answer the research questions that have guided this study. This chapter presents these results in alignment with each research questions. The first research question was: What are the barriers and success factors associated with sustainable event management of music festivals? This question will be answered in two parts. First, the results present the barriers associated with sustainable event management of music festivals. Next, the results present the success factors associated with sustainable event management of music festivals. Last, the second research question is answered. What, specifically, do music festival organizers need to improve the sustainable event management of their festivals?

\section{What are the Barriers Associated with Sustainable Event Management of Music Festivals?}

Data collected from the open response portion of the survey and supplemented with interview data gave way to very interconnected results that inform the barriers associated with the sustainable event management of music festivals. The study participants were asked to describe the challenges they have encountered with sustainable event management and specific needs that would help them improve sustainable event management of their festivals. Through analysis of this data, seven key barriers were 
derived and will be discussed according to prevalence. These seven barriers are presented in Figure 5, and then discussed in more detail.

Figure 5. Analysis of the barriers associated with sustainable event management of music festivals.

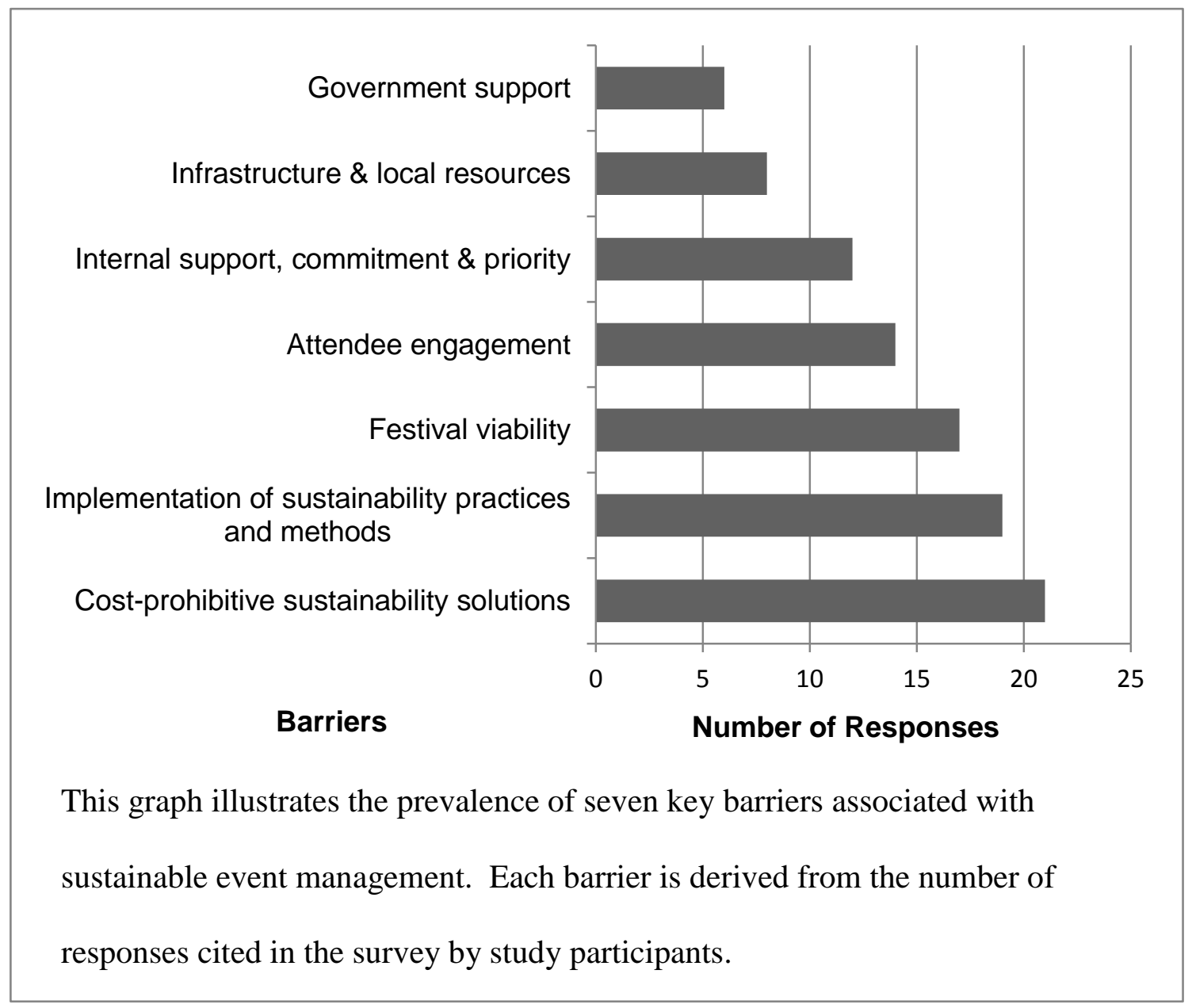

1) Cost-prohibitive sustainability solutions. The combination of increased costs of sustainability initiatives and limited resources to put toward sustainability initiatives creates the greatest barrier associated with sustainable event management of music festivals. Chris, of Gathering of the Vibes Music and Arts Festival in Bridgeport, Connecticut, explains the festival's experience with this barrier well: 
The main challenge is the financial challenge of being able to implement initiatives so that it doesn't eat into the bottom line and so the event can survive for more years. Part of that is keeping costs down. How can we be creative and make real progress that is not going to be so costly that it scares off the promoter? (Chris, personal communication, March 9, 2011)

This barrier is complex because it can manifest in different ways. The participants expressed three different angles to this barrier. The first angle is the challenge of allocating resources toward sustainability measures. For example, to support Bonnaroo Music and Arts Festival's power from entirely renewable solar energy, the festival would need to make a financial commitment that wouldn't see a return on investment for ten to fifteen years (Terry, personal communication, February 23, 2011). The festival needs to balance investment with return, and this cost poses a significant risk to the festival's health. The second angle is the challenge of acquiring the necessary resources in the form of finances, staffing and time. A small festival may have the know-how to initiate a compost-collection program, but if that festival doesn't have access to the necessary volunteer support or the time required to train and organize that volunteer support, then an effective program cannot be implemented. The third angle is identifying cost-effective solutions when sustainability materials, alternatives, and practices are more costly than conventional ones. For example, if a mid-sized festival wants to reduce the volume of its disposable waste products, should the festival hire a water truck to minimize disposable water bottles or purchase compostable serviceware to reduce disposable food and drink waste? Both potential solutions pose increased costs for the festival. It is important to 
recognize these different angles from which a single barrier can be approached, because solutions can be found in these different perspectives. What these different angles seem to boil down to is that music festivals are struggling to balance the increased cost of sustainability initiatives with the economic viability of their festivals. Morgan, of South by Southwest in Austin, Texas, explains the challenge of the increased costs of sustainability initiatives:

These [increased costs] make environmentally sustainable initiatives not economically sustainable. For a sustainability solution to be viable, it needs to be economically feasible, and can't get in the way of what we are trying to do. If it increases operations overhead by 28 percent, it is not sustainable. When the public decides this is the route we want to take, then costs will decrease. (Morgan, personal communication, February 26, 2011)

In essence, music festival organizers perceive the movement in a sustainability direction as cost-prohibitive, and thereby the most significant barrier to improving sustainable event management of music festivals.

2) Implementation of sustainability practices and methods. The second most significant barrier associated with sustainable event management of music festivals is the identification and implementation of sustainability practices and methods. To clarify, this barrier is not related to the costs of sustainability initiatives, rather it is related to the execution of sustainability initiatives. Survey comments that comprise this barrier included difficulties with identifying sustainability issues, understanding the scope of solutions and integrating sustainability into festival decision-making. Additionally, 
several comments were specifically about the challenges of implementing sustainability methods, such as controlling vendor products and upstream materials for compost collection and waste management, and locating partners to forge partnerships with mission-aligned organizations. One participant explains the need for help identifying and implementing sustainability practices:

A packaged, cost efficient group/company could work with each festival on consulting and implementing sustainable practices. It would need to work within the production framework already in place, understanding the challenges and possibilities for each festival. This may already exist, but it hasn't come across my desk! (anonymous, personal communication, December 7, 2010)

This comment describes how festival organizers would benefit from assistance figuring out sustainability solutions. Similarly, another survey comment explains that "a model of time and cost efficient [sustainability] methods that have been proven successful would be of great service" (anonymous, personal communication, December 9, 2010). This barrier can be interpreted as the road blocks that are scattered throughout the road toward sustainability. Music festival organizers are struggling to design sustainability solutions, adopt appropriate practices and implement effective methods. Additionally, this barrier involves making changes to the way the festival already operates, including matters of organizational change for sustainability, which can be extremely difficult.

3) Festival viability. Sustaining festival viability and longevity is the next most significant barrier that music festival organizers face in sustainable event management of music festivals. Event organizers are challenged to sustain their festivals' ability to grow 
and survive in various capacities. This barrier is different from the others because it may or may not be related to the challenges incurred with environmental sustainability practices. Rather, it is centered on economic sustainability. Some survey comments that represented this barrier include the challenges of "outgrowing the festival site," "accommodating thousands of people effectively," and "keeping artist lineup current enough to attract and maintain a younger audience without alienating our older clientele." These are challenges that must be addressed to sustain festival health and viability. While some aspects of this barrier deal with various external or changing forces, much of the barrier deals strictly with securing enough funds to ensure that festivals can sustain themselves economically. Oddie, of the Lionel Hampton Jazz Festival in Moscow, Idaho, explained how music and arts festivals cannot survive on earned income alone and must find additional income to remain viable (personal communication, March 11, 2011). These additional sources of income are becoming less available, particularly during the current economic recession. The struggle to sustain festival viability and longevity is eloquently communicated in the following survey comment:

Our festival, like many other arts organizations, is finding it more and more difficult to "make a profit." So, that part of the triple bottom line sustainability is becoming weaker as time goes by, mostly due to the trouble our nation and our particular rural geographic area are having economically. (anonymous, personal communication, December 15, 2011)

This survey comment explained how the barrier of sustaining festival viability is most associated with the economic dimension of sustainability before the social or 
environmental dimensions. Other survey comments relating to this barrier note the challenges of "increased cost of talent," "keeping event viable with increasing competition," and "alternatives to generating income without charging admission." This barrier is one of achieving economic sustainability so that festivals can survive for longterm duration. An important part of sustainable event management is sustaining music festivals in a healthy capacity so that they can survive.

4) Attendee engagement. Generating attendee education, participation and engagement around sustainability awareness and festivals' sustainability initiatives is the fourth barrier associated with sustainable event management. Attendee engagement and participation around sustainability initiatives is imperative to a festival's sustainability progress because attendees are active and central stakeholders of music festivals. This means that the degree to which attendees participate in a festival's sustainability initiatives will influence how effective those initiatives will be. The more educated and enthused attendees are about a festival's water conservation program, the more attendees will be willing to make conscious efforts to minimize water bottle usage. Some survey comments that describe the barrier of generating attendee engagement include "difficulty getting attendees to adopt new habits and practices when they are only in our presence for a weekend," "changing behavior at events," and the need for "more attendee awareness." Chris, of Gathering of the Vibes, described the challenge of engaging attendees:

When you have a major festival, the entertainment is the main thing. Even if you have a very aware crowd, it can be hard to connect with them when everyone is in party mode. You need to work engagement strategies into the mix in a way that is 
fun and appealing. The challenge is finding creative ways to bring them in that isn't subjecting them to a dry lecture. (Chris, personal communication, March 9, 2011)

In this quote, Chris described the difficulty of strategizing different ways to connect and educate attendees about sustainability issues and the festival's sustainability initiatives. Other survey comments cited the difficulties of implementing practices to boost attendee engagement such as "strategizing pre-event promotions," "making on stage announcements" and crafting "incentive systems to encourage attendee participation in sustainability initiatives." Seen as a barrier, attendee engagement and participation is in sustainability is difficult to achieve, but it is a critical element that will influence the effectiveness of other sustainability practices.

5) Internal support, commitment and priority. The fifth barrier associated with sustainable event management involves gaining support, commitment and priority from the whole festival body to move in a sustainable direction. Survey comments that related to this barrier primarily surrounded two primary issues: generating support from top management and decision makers, and streamlining communication within the festival organization. Some comments that describe this barrier are "ownership not understanding the importance of sustainability to the brand," difficulty gaining "interdepartmental communications and support of initiatives," and a need for "a team of decision makers that make the triple bottom line their priority." One participant described the difficulty of encouraging the whole festival organization to support and participate in a sustainability direction by describing the need for "greater financial 
commitment to sustainability initiatives as well as strong leadership from department heads to support initiatives - sustainability needs to be everyone's job!" (anonymous, personal communication, December 16, 2010). These results suggest that the barrier of gaining internal support, commitment and priority may stem from sustainability being treated or perceived as a separate arm or compartment within the festival organization.

6) Infrastructure and local resources. Limited infrastructure and local resources of the host site, community or region was cited as a barrier to sustainable event management moderately in the survey open response questions, but discussed quite thoroughly in each of the interviews. Some survey comments that describe this barrier include the "lack of transportation and transportation infrastructure," and "lack of infrastructure and weaknesses in legal system to implement sustainable practices: e.g. lack of recycling facilities, lack of composting facilities, illegalities of composting toilets and on-site composting, etc." Oddie, of the Lionel Hampton Jazz Festival, further explains the limitations imposed by a lack of infrastructure and local resources:

What is unique about [the Lionel Hampton Jazz Festival], whatever the standard is for the host community and the university with respect to facilities management and sustainability, recycling and those efforts, that's the baseline. At the University of Idaho, facilities do not provide event recycling. I can see where I can help to develop programs. But it's almost like I have to back up a little, otherwise I'll have to establish a recycling program for the whole university. (Oddie, personal communication, March 11, 2011) 
If a host community does not have an adequate supply or kind of infrastructure necessary for festivals to reach their sustainability goals, then the sustainability opportunities of that festival are immediately restricted. Without supportive infrastructure and local resources, it is irrelevant whether the festival organizers have the necessary know-how, organizational support, staffing or a number of other enabling resources.

Another example of this barrier is demonstrated by the experiences of South by Southwest. The scale of the festival is so large that the host city of Austin, Texas lacks enough sustainable infrastructure, including composting collection, recycling hauling, and low energy technology, to meet the festival's needs (Morgan, personal communication, February 26, 2011). Morgan explained that once a festival maximizes the use of the local infrastructure, there is a need to either supplement with private and outside sources, or forgo the particular sustainability initiatives all together. While limited infrastructure and local resources can be extremely limiting forces to sustainable event management, if music festivals are going to mitigate their negative impacts and cultivate their positive impacts, then solutions must be devised to alleviate this barrier.

7) Government support. A lack of government support is the last of the seven key barriers associated with the sustainable event management of music festivals. This was the least discussed and referenced of the barriers, but was still described as quite a significant challenge and an important need. Survey comments citing this barrier pointed to the need for improved government funding, support and communication. Some survey comments also suggested that sustainable event management would be 
improved with "legislation requiring sustainable event management in the permitting process" and "using incentives and mandates to help achieve sustainability goals." Music festivals can only progress toward sustainability and take leadership if they are given the necessary support from government bodies and regulations.

These seven key barriers associated with sustainable event management are derived directly from event organizers' experience and perspectives engaging sustainability of United States music festivals and the needs and challenges they have encountered in their work. These barriers begin to provide a better understanding of the current state of sustainable event management of United Stated music festivals. To provide a more complete picture, the results to the second part of this research question must be presented.

\section{What are the Success Factors Associated with Sustainable Event Management of Music Festivals?}

Results that inform the success factors associated with sustainable event management were drawn from the survey data, primarily the Likert-scale, and supplemented with interview data. The Likert-scale asked participants to identify the factors that would be most effective in helping them improve triple bottom line sustainability of their music festivals. This data collection instrument was designed to gain an understanding of success factors that would be most beneficial to music festival organizers. The Likert-scale results are exhibited in Figure 6. 
Figure 6. Factors that may improve sustainable event management

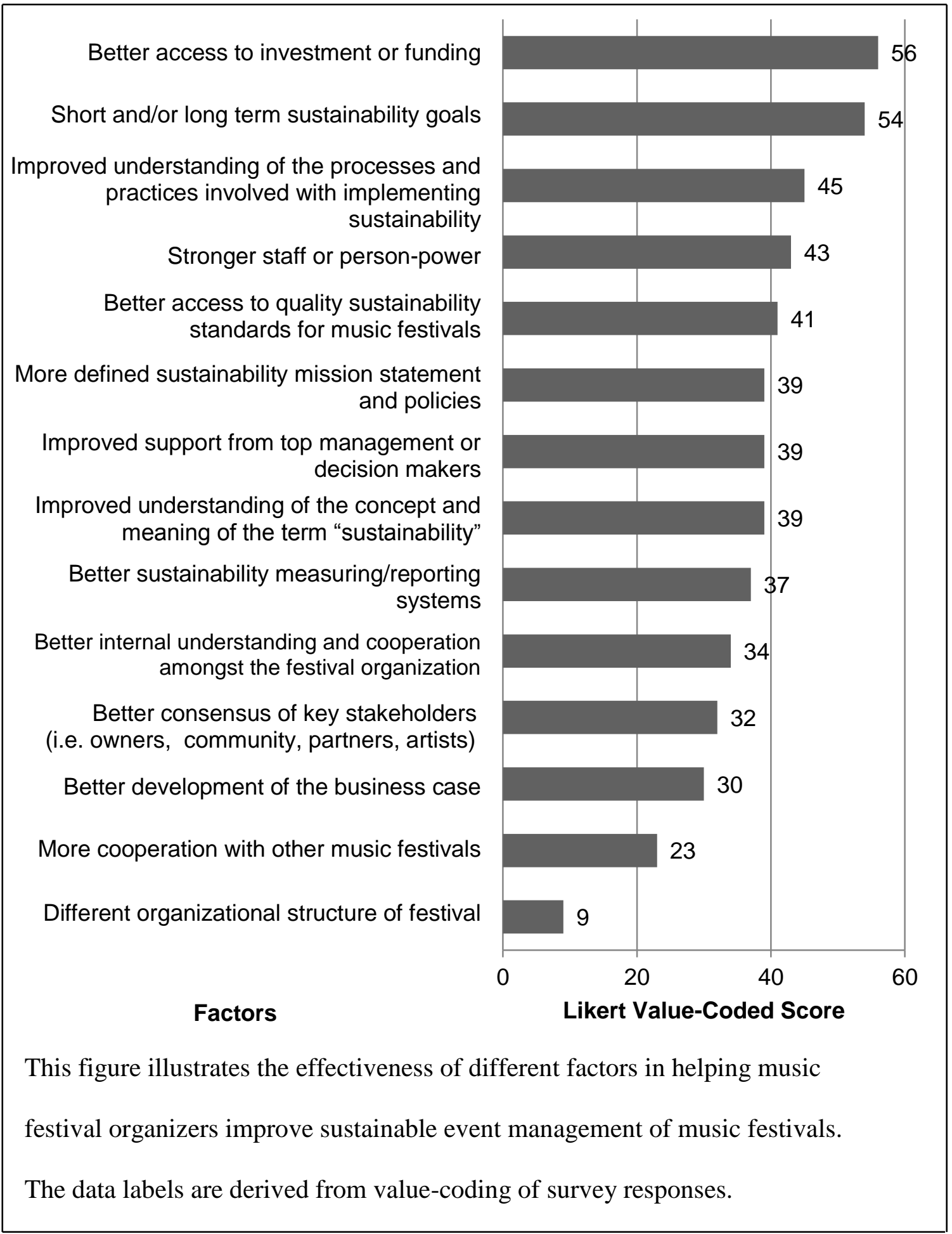


The Likert-scale results show that the participants rated two factors more effective than any of the rest in helping organizers improve sustainable event management of music festivals. "Better access to investment and funding" was rated as the most effective factor. The "development or improvement of short and/or long term sustainability goals" was rated the second most effective factor. Most of the other remaining factors were rated very closely, aside from the final two factors. More cooperation with other music festivals and a different organizational structure of the festival were rated to be least effective at helping music festival organizers improve sustainable event management. These results were combined with interview data and open response questions to determine four primary success factors associated with sustainable event management of music festivals. These four success factors are not arranged in any particular order.

Including sustainability in festival goals. The results show that including sustainability issues in festival goals is a success factor associated with sustainable event management. 'Short and/or long term sustainability goals' is a factor in the Likert-scale that was rated extremely highly by the survey participants. The inclusion of sustainability in festival goals also emerged from the interviews as a prominent success factor. Kerrie, of the Petaluma River Revival Festival in Santa Rosa, California, described how sustainability is a central goal of the festival, "For Petaluma, sustainability is a priority goal and has a mission statement to celebrate community, history, culture and geographyall of which are deeply ingrained in sustainability" (personal communication, February 23, 2011). Similarly, when Chris was asked to attribute the success factors behind the 
sustainability achievements of Gathering of the Vibes, Chris described the festival's ability to "gather enough people who care and who are willing to work together for a shared goal" (personal communication, March 9, 2011). However, most music festivals don't include sustainability as a central theme or in a central mission statement. Terry, of Bonnaroo, explained that only the music festivals that have a focus on sustainability can get to full mitigation of their negative impacts (Terry, personal communication, February 23, 2011). Bonnaroo is a for-profit venture and their business is being a music and arts festival - they aren't in the business of sustainability (personal communication, February 23, 2011). Even so, Bonnaroo has achieved great feats in sustainable event management. Terry explained that Bonnaroo just tries to make the best decisions they can, and "the goal is to see sustainability and greening be incorporated to the festival whenever possible" (personal communication, February 23, 2011). For these festivals, sustainability may not be the central goal, but it is included in the greater scope of the festivals' goals. Therefore, the intention of including sustainability in festival goals is a success factor associated with sustainable event management of music festivals.

Understanding context, relationships and networks. A second success factor that emerged from the study results is the importance of understanding and investing in a festival's context, relationships and networks. Oddie, of the Lionel Hampton Jazz Festival, described how understanding the context, local culture and dynamics of music festivals is critical to the festival's sustainability:

To keep these events sustainable, you really, really have to understand the context of the region and the relationships that have been built. Because when those 
relationships get severed, it's like Alzheimer's or something. The event can't remember where it got garbage dumpsters, or how, and then the pricing escalates when you have to replace them. (personal communication, March 11, 2011)

Oddie explains that there are all kinds of variables and dynamics that make each festival different. To keep a festival sustainable, the event organizer must understand the context of each festival, examine the connections and relationships that exist in the local community, identify the cultural distinctions of each place, and listen to the dynamics throughout the geographical location (Oddie, personal communication, March 11, 2011). Similarly, Chris, of Gathering of the Vibes, describes how the festival's ability to build and maintain strong relationships has been an important success factor to sustainable event management:

We have good relationships with other people in the community. For example, I just had a conversation with the director of a state agency. Really the thing that has been most effective is being able to reach out and network and tap into the expertise that is out there. Not all of us can be an expert on everything. We have great contacts with non-profits locally and regionally and have built a strong relationship with city. (Chris, personal communication, March 9, 2011)

Keeping the connections and relationships that support the festival healthy not only builds resilience, but it increases festivals' potential for longevity. It is important to remember that all music festivals exist in contexts, relationships and networks that connect them to specific places and cultures, even if those connections aren't effectively maintained. Thus, understanding and investing in the particular contexts, relationships 
and networks of each music festival is an important success factor associated with sustainable event management.

Attendee engagement. Attendee engagement and participation with sustainability initiatives emerged from the study results as a third success factor associated with sustainable event management of music festivals. The fact that attendee engagement can act as both a barrier and a success factor shows that it can be difficult to get attendees engaged with a festival's sustainability direction. However, once attendees become engaged with sustainability learning, that festival's progress toward sustainability much improves. Terry suggests that much of Bonnaroo's progress in sustainability is directly connected to successfully educating and empowering the festival's attendees (Personal communication, February 23, 2011). Terry further explained that music festival fans are active, important stakeholders and "as they become more aware and educated around sustainability, [Bonnaroo's] sustainability strategies make more of an impact" (Personal communication, February 23, 2011). Similarly, Kerrie, of the Petaluma River Revival Festival, explained that music festivals have a much greater opportunity to take leadership in sustainable event management than other kinds of events because the attendees are active participants of the festival (personal communication, February 23, 2011). This means that the very phenomenon of music festivals makes it impossible for attendees to be passive observers in their gathering and celebratory nature. This survey comment describes how this event organizer finds success in sustainable event management, "Being consistent, using education, building relationships and continuing to change behavior by making it fun" (anonymous, personal communication, December 18, 
2011). The more attendees become engaged with sustainability learning, the easier it is for the festival to move in a sustainable direction.

Support from top management and decision makers. The last success factor associated with sustainable event management of music festivals is the support from top management and decision makers of the festival's sustainable direction. Several survey comments cited the importance of top management support for sustainable event management progress, and further discussion of this success factor appeared in the interviews. Terry, of Bonnaroo, attributes some of the success of the festival's sustainable event management to:

the willingness of the department heads to try to make change. I'm lucky that I have such a supportive department head. They've come up with a couple different ways to generate some income to do some improvements on site, the victory gardens and compost pads, and signage initiatives. (personal communication, February 23, 2011)

Additionally, Chris of Gathering of the Vibes, notes that many of the sustainability initiatives of the festival would not have been achieved without the support and financial backing of the festival's ownership (personal communication, March 9, 2011). With support from top management and decision makers, energy can be invested in moving the festival in a sustainable direction rather than educating and persuading the internal team with sustainability awareness and priority. This makes support from top management and decision makers an important success factor associated with sustainable event management. 
The study results revealed these four success factors as key areas that have been most effective at helping event organizers progress their music festivals in a sustainable direction and reach achievements that have made their festivals more environmentally, socially or economically sustainable. The state of sustainable event management of music festivals from an event organizer perspective is now clearer. Before these results are discussed, the last research question that has guided this study must be answered.

\section{What, specifically, do music festival organizers need to improve sustainable event management of their festivals?}

This study proposed a second research question to further create a more complete understanding of the state of sustainable event management of music festival through an event organizer perspective. The purpose of this research question was to capture any underlying needs of music festival organizers outside of the barriers and success factors already gathered. The results pointed to three specific needs not already touched upon as barriers or success factors to improve sustainable event management of music festivals.

Improved understanding of sustainability practices and methods. The survey participants rated 'an improved understanding of sustainability processes and practices' the third most effective factor likely to help move festivals toward sustainability in the Likert-scale. Combined with a significant barrier being implementation of sustainability methods and practices, this evidence shows the existence of a gap in sustainability understanding of practices and methods. There is a need for event organizers to have a better understanding of sustainability practices and the implications of practices in creating the most good and least harm. There appears to be confusion around the most 
appropriate hierarchy of sustainability operations. Specifically, in what order should recycling, durable serviceware, energy efficiency, renewable energy, grey water collection, product purchasing, social impact assessment, community partnerships, local and organic food options, or compostable toilets be addressed? Which practices should be implemented in which order, and how can they be implemented appropriately? For example, should an event organizer choose to use reusable beer cups, compostable beer cups or recyclable beer cups? There is no sense in wasting resources, energy and time while each festival learns how to implement an effective recycling program. "It's hard and inefficient for every festival to try to reinvent the wheel" (Terry, personal communication, February 23, 2011). Much of this confusion can be resolved by sharing successes, failures and experiences of sustainability practices and methods.

More accurate perception of sustainable event management. A second need of event organizers that emerged from the results is a more accurate perception of sustainable event management. A positive attribute derived from these results that will contribute to the success of the music festival community as a whole is recognizing the importance of sustainability. The results indicated that sustainability is very important to music festivals represented in the study. On average, the study participants rated the importance of sustainability concepts, practices and processes to their festivals " 8.5 " out of " 10 ". The participants were also asked to rate the economic, social and environmental sustainable event management initiatives of their festivals. The results showed that the study participants regard the sustainable event management of their own festivals quite highly. On average, the survey participants rated the economic sustainability initiatives 
of their festivals "7.6" out of " 10 "; they rated the social sustainability initiatives of their festivals "8.6" out of "10"; and they rated the environmental sustainability initiatives of their festivals "7.7" out of "10." Averaged together, the study participants rated the economic, social and environmental sustainable event management initiatives of their own festivals at a score of "8.0" out of "10." However, when asked to rate the current state of triple bottom line sustainability throughout the United Stated music festival community as a whole, the study participants rated the music festival community "5" out of " $10 . "$

These results show that participants don't have a clear understanding of the sustainability of their festivals in regards to the rest of the festival community. Acknowledging the possibility that the participants may be more involved in sustainability simply due to their willingness to participate in the study, the above figures show a discrepancy in perception. This discrepancy is interpreted to mean that either the participants perceive their festivals to be more sustainable than they are, or other festivals to be less sustainable than they are. Regardless, there exists a misperception of the state of sustainable event management of United States music festivals. The researcher also noticed the issue of perception when participants showed disinterest in participating in the study because they found themselves unaffiliated with sustainability even though their festivals clearly demonstrated strong benefits and contributions to their host communities. Perception is slightly touched upon in the free response portion of the survey. The study participants likely didn't bring forth the challenge of perception as an immediate barrier to sustainable event management because they aren't aware of it. 
These results demonstrate a need for music festival organizers to have a more accurate perception of their festivals' sustainable event management. If event organizers don't fully understand the current state of their festivals' sustainability, how can they effectively plan sustainability programming to move their festivals to an improved state of sustainability?

Improved sustainability standard for the sector. An improved standard baseline for sustainable event management is the final need of event organizers to improve sustainable event management of music festivals. The results revealed that the current standard is from sustainable event management generally equates to a recycling program. This standard is just too low for sustainable event management to be widely adopted and expanded to common practice. Survey participant comments also described the need for, "industry standards set that festivals have to reach to be considered a sustainable event, make it something that festivals want to conform to" (anonymous, personal communication, December 16, 2010). Similarly, another survey participant noted the challenge imposed from differing regional sustainability standards. It is hard for music festivals to replicate sustainability practices because of differing standards and expectations of sustainability across the country. Therefore, event organizers need an improved standard for sustainability within the music festival sector in order for music festivals to better move toward sustainability.

\section{Conclusion}

These needs, combined with the barriers and success factors that organizers have encountered in moving their music festivals toward sustainability, have created a good 
picture of the issues surrounding sustainable event management through an event organizer perspective. Now with this better understanding, strategies can begin to be formulated to improve sustainable event management of United States music festivals. The next chapter will discuss the findings in the greater context of the foundational information provided by the literature review in Chapter 2. By discussing these findings in a greater context, recommendations can be drawn to provide strategies to help event organizers improve the sustainable event management of music festivals. 


\section{Chapter 5: Discussion of Findings}

The purpose of this study was to investigate the challenges and success factors of sustainable event management to identify strategies that will help event organizers improve sustainable event management of music festivals. Sustainably managed music festivals can be a significant societal asset in the greater transition to sustainability. Music festivals have many valuable benefits that can fill a unique niche in a sustainable and desirable future if they are properly designed, envisioned and managed for sustainability. Therefore, music festival organizers are in need of strategies that will help them effectively mitigate the negative impacts of music festivals while cultivating their positive ones. This chapter reviews the study findings presented in the previous chapter in the context of lessons learned in the literature review of Chapter 2. From this discussion the writer presents several recommended strategies. Lastly, the paper concludes with a closing summation and final thoughts.

The results of this study revealed important findings that shine light on the state of sustainable event management of United States music festivals through an event organizer perspective. Seven key barriers associated with sustainable event management of music festivals were identified as: cost-prohibitive sustainability solutions, the implementation of sustainability practices and methods, sustaining festival viability, building attendee engagement, gaining internal support, commitment and priority, limited infrastructure and local resources, and limited government support. In addition, findings of the study revealed four success factors associated with sustainable event management which are: the inclusion of sustainability in festival goals, understanding context, 
relationships and networks, building attendee engagement, and gaining support from top management and decision makers. Lastly, the study findings revealed three additional needs of event organizers which are improved understanding of sustainability practices and methods, a more accurate perception of sustainable event management, and an improved sustainability standard for the music festival sector. These findings will be discussed as the recommended strategies are presented.

\section{Recommended Strategies}

To improve sustainable event management, seven strategies were crafted from these barriers and success factors and the needs of music festival organizers. The strategies were built upon the foundation laid by the literature review in Chapter 2. This means that these recommended strategies incorporate sustainability theory and practices, previous research on sustainable event management, existing strategies of sustainable events, lessons drawn from organizational change studies, and the results from this study. The strategies are not presented in order of importance. Rather they are presented in order of ease of implementation. More specifically, the strategies presented first can be implemented by individual festivals, and the latter strategies are recommended for all of the United States music festival community.

1) Use sustainability framing and long term planning. The first strategy proposed for improved sustainable event management of music festivals is the use of sustainability framing and long term planning. The results showed that music festivals may not be using short or long term goals which are a very important beginning stage of organizational change for sustainability. In addition, the study results showed that 
festivals don't have a clear perception of their own state of sustainable event management or a clear understanding of sustainability practices and methods. This evidence combined shows that music festivals organizers may not be using sustainability framing for strategic planning.

When organizations use sustainability framing either formally or informally, they are transitioning through the stages of organizational change for sustainability. This means that organizations transform from a business as usual framework of management, production and operations to a frame of reference centered in sustainability. Therefore, re-orienting the framing of a music festival toward sustainability will help that festival adopt a sustainable structure of concepts, values and processes. Rather than launching fragmented sustainability initiatives, music festivals should use sustainability framing to follow the stages of organizational change for sustainability. Several articles were synthesized in the literature review of Chapter 2 to produce these stages of organizational change for sustainability: create a shared vision, create goals and indicators, make changes in basic operations, redesign processes and systems, create innovation, and finally restructure and rebuild business models (Grey, Walters, Bebbington, \& Thompson, 1995; Luban \& Esty, 2010; Senge, 1990; Senge, 2008; Sharp, 2002; The Natural Step, 2009). Adopting a sustainability framework and understanding this progression of organizational change will help music festivals build a sustainable direction and priority within the festival organization.

Many music festivals have taken on sustainability initiatives that make changes in the festival's basic operations like waste management and energy conservation but 
haven't crafted a shared vision or specific goals that will guide the festival toward that vision. Senge (2008) stresses the importance of these steps, and asserts that the best kind of shared vision is a work in process that evolves over time. Once a music festival has effectively launched sustainably initiatives, the next level of sustainable event management pushes beyond operations-based projects to greater systemic transformation of the organization. Moving into systemic sustainability means streamlining operational processes, working with suppliers and partners to innovate new strategies, and integrating sustainability throughout departmental decision-making and organizational policies (Lubin \& Esty, 2010; Senge, 2008; Sharp, 2002). Lightning in a Bottle Festival, in Irvine, CA, is a phenomenal example of a music festival that is continually designed, managed and operated in a sustainability framework. The festival has a stated vision and mission, each year sets goals and indicators, has integrated sustainability policy and process throughout the festival's systems, and has structured a business model that demonstrates sustainability framing (The Do Lab, 2010).

Part of creating a shared vision for sustainable event management is putting it in a long term plan. Long term planning is necessary not only to help a festival transition into a more sustainable organization, it is critical to leaving a positive legacy with those whom a festival impacts. Maintaining a long-term perspective will also help organizers make decisions that are more sustainable. The literature showed that a failure to incorporate good long term planning into festival design can leave harmful and unsustainable impacts on host communities and regions (Robertson, Rogers, \& Leask, 2009; Smith, 2009). Long term planning can help a festival build collaborations in the 
host community, strengthen roots in place, partnerships, etc. Additionally, environmentally sustainable solutions may seem cost-prohibitive in the short term, but may become more amenable when strategically planned for the long-term. With a five to ten year strategic plan, music festivals can save money for projects that have a longer return on investments such as solar installations, dish-washing stations, efficient stage lighting or other environmentally sustainable improvements. Long term strategic planning is another way for festivals to break past the barrier of cost-prohibitive sustainability solutions.

The recommendation to use of a sustainability framework shows consistency with the recommendations of the study by Brooks, O’Halloran and Magnin (2007). The Brooks et al. study produced a guidebook that uses of the Natural Step Framework to help music festival organizers create a strategic sustainability plan. This thesis supports the Brooks et al. recommended guidebook and use of the strategic sustainability planning, The results of this study showed that music festivals are in very early stages of organizational change for sustainability and have yet to fully grasp a clear perception of their own state of sustainable event management. This shows that music festival organizers may not have the capacity nor be quite prepared for full strategic planning for sustainability transformation. Therefore, this thesis suggests that music festivals should ease in to sustainability framing slowly with incremental steps of organizational change for sustainability. Simply creating a shared vision and goals to support and guide a festival's sustainability initiatives will be extremely beneficial. Continuing to follow these steps will help organizational change for sustainability emerge. 
2) Exercise a holistic scope. The next recommended strategy is for music festival organizers to exercise a holistic scope in sustainable event management. Exercising a holistic scope means engaging the festival with all its component parts rather than focusing on the workings or functionality of only certain pieces of the festival. This is the difference between a holistic and a conventional, reductionist scope. Exercising a holistic scope is putting in action the ideology that the whole festival is greater than the sum of its parts. Realizing the wholeness of organizations in all their interconnected pieces is central to sustainability theory (Meadows, 2008). Therefore, event organizers should strategically plan for economic, social and environmental sustainability all at once, because these three dimensions are interdependent upon one another.

Exercising a holistic scope will help music festivals move past the perception that sustainability equates to an environmental add-on. Although the open response portion of the survey asked participants to describe their challenges and needs to triple bottom line sustainable event management, most of the responses gathered were in reference to environmental sustainability. The bulk of the responses gathered are ones that would be expected had the questions been phrased with the term "event greening," because they primarily pointed to solutions and practices that seek to minimize the negative environmental impacts of music festivals. Therefore, a very conclusive result of this study is that sustainability is often perceived by music festival organizers as an environmental add-on that is cost-prohibitive and difficult for the festivals to accommodate. While it is true that much of the harmful impacts of music festivals are within the environmental realm, many of the success factors associated with sustainable 
event management have to do with improving social dynamics. Maintaining relationships with stakeholders, understanding community networks, engaging attendees, and building community partnerships are all success factors that manifest in the social realm. Economic viability and longevity are related to social cohesion and maintaining community networks. Building financial investment for new environmental initiatives is related to gaining buy-in and support from stakeholders. Implementing fluid environmental sustainability processes is improved through educating and building enthusiasm in attendees. These are just a few examples of the interconnections between the different dimensions of sustainable event management. Therefore, to effectively mitigate a music festival's environmental impact, all parts of a festival should be undertaken and addressed holistically.

Music festivals must be engaged, planned and operated as whole interconnected systems rather than compartmentalized into pieces. Just like the living system of an organism, music festivals are a whole operation of moving parts that produce their own patterns of behavior and are dependent on internal and external subsystems (Capra, 2002). If event organizers continue to view sustainable event management as simply "greening," the environmental arm of sustainability will always be a separated. Similarly, if event organizers keep trying to do business-as-usual while shading some operations 'greener,' then sustainability solutions will always be cost-prohibitive. Embracing sustainability at is most fundamental level requires a conscious effort to move past separation and toward integration (Sterling, 2001). This means that exercising a holistic scope will help festivals adopt a sustainable direction and priority of the whole 
festival body. If the sustainability coordinator or department is treated as a separate arm of the festival organization, that festival's sustainability progress will remain limited. Moreover, exercising a holistic scope is necessary to achieving the benefits acquired by the later stages of organizational change for sustainability. Festivals will not be able to progress from project-based sustainability initiatives to systemic organizational sustainability if they continue to compartmentalize sustainability as a separate part of the festival. Rather, sustainability awareness, design and decision making must be integrated throughout the whole organizational system (Sharp, 2008). Event organizers can work toward these objectives by actively nurturing the festival's supporting relationships, understanding the festival's context and ecology, and investing in community networks of the host site and region (Robertson, Rogers \& Leask, 2008). Exercising a holistic scope is an important step of improved sustainable event management for United States music festivals.

3) Invest in attendees with sustainability education. The third recommended strategy for improved sustainable event management is investing in attendees with sustainability education. The study results showed that attendees are a critical stakeholder to music festivals, and that improved attendee engagement, education, and participation is a leverage point for change. The more engaged the attendee base is with sustainability learning, the more effective a festival's sustainability initiatives will be. In addition, stakeholder engagement and participation is noted in the literature as an important strategy to successful sustainability initiatives and long-term viability of the festival (Anderson \& Getz, 2008, Laing \& Frost, 2009). Therefore, this thesis 
recommends that attendees should be invested in with sustainability education through awareness, design, experience and transformative learning.

It is imperative that awareness is generated about the festival's sustainability initiatives and related sustainability issues amongst attendees. Every music festival should be transparent and explicitly communicate its sustainability initiatives and successes on its website, social media, newsletters, pre-event promotions, annual reports and any other outlets. It is also important that this messaging is sufficiently communicated throughout the festival site. Making attendees aware if all the festival's sustainability practices and why the festival is making such initiatives are imperative in order to encourage attendee's participation in such initiatives. This thesis suggests that a festival's sustainability practices cannot be over-communicated to attendees. Creative awareness generation beyond these basics communications should be based on the festival's specific place and context and should relevant to the local culture (Grenwald, 2005). Some kinds of creative communication campaigns will be better received with specific cultures than others, and it is important not force or preach values or lifestyles to attendees.

Attendees should be educated through the design and demonstration of the festival itself. The design of the festival, the architecture of its spaces, and the materials and resources that flow through the festival create a hidden curriculum that will subtly educate attendees (Orr, 2004). The kinds of partners, food vendors, service providers and sponsors chosen to collaborate with the festival will also educate attendees for the better or for the worse. All these individual parts of the festival together contribute to the 
festival's whole direction, and are therefore opportunities to demonstrate sustainability education. Explicit and clear messaging signage should be posted in key places of the festival site that connect to sustainability practices. For example, the festival should explain how much water is being used and where it came from, what kind of lighting is used and what partner provided it, how much energy is being saved and from where it was sourced, and how much waste is produced on site. This is an opportunity to influence ecological literacy by pointing out ecological principles on the festival site such as networks, cycles, partnerships, diversity and solar energy (Capra, 2002).

Experiential education is a key opportunity of music festivals, because participation of attendees is a defining characteristic of music festivals. Experiential education is extremely powerful because it helps learners engage, investigate, reflect and internalize their learning (Higgins, 2009). Therefore, attendees need interactive and participative experiential opportunities to engage with sustainability at music festivals. Results of the study showed this is both a barrier and success factor associated with sustainable event management. This means that attendee engagement is difficult to achieve, but extremely effective once attained. This thesis recommends event organizers launch a combination of fun and responsibility-oriented experiential activities. Engagement with sustainability concepts can be in the form of games or art, discussions with non-profits or partners, or interactions with sustainable technologies. Responsibility-oriented participation like cleaning up waste, recycling, or alternative transportation generally often requires incentives. Many music festival organizers are already launching great campaigns like Carpoolchella, a campaign that rewards attendees 
for carpooling at Coachella Festival in Indio, California (Jones \& Scanlon, 2010). Another example is the Rock and Recycle campaign at Lollapalooza Festival allows attendees to earn awards and discounts for merchandise when gathering recycled materials (Jones \& Scanlon, 2010).

The most impactful sustainability education opportunity of music festivals is arguably that of transformative learning. Transformative learning is a deeper-level, creative kind of learning that transforms some part of the way the learner sees of the world and invokes new views and ways of doing things (Cranton, 2002; Sterling, 2001). It can "occur gradually or from a sudden, powerful experience, and changes the way people see themselves and their world" (Clark, 1993, p. 10). Music festivals are excellent opportunities for transformative learning because they are sources of powerful, soulful and sometimes mystifying experiences. Dr. Andre Soars (as cited by Jones, 2010) of Boom Festival in Portugal explains how music festivals can cultivate transformative learning:

Events such as Boom have a transforming potential in many ways. Firstly, the gathering of thousands of people in a specific place for a limited amount of time is an opportunity for reflection on the communitarian nature of our species: How do we live together? How do we relate? How do we occupy space? What do we leave behind? What is our ecological function in the web of life? How do we satisfy our survival needs in equilibrium with the needs of all other species? These questions can be instigated at any event, even when music and art are the main focus. (p. 5) 
Transformative learning for sustainability is extremely valuable because it empowers learners and encourages them to be critical thinkers and leaders. Event organizers can design music festivals to encourage transformative learning by providing opportunities that support the facets of transformative learning progression. The powerful experiences provided by music festivals are not enough to encourage this kind of learning. Transformative learning requires evaluation of the learners' views, openness to alternative perspectives, discussion and reflection (Cranton, 2002). Event organizers can work to support these facets in a variety of ways. Different kinds of perspectives can be provided through guest speakers, representatives of non-profits or signs with inquisitive quotes or questions. Music festivals might incorporate quiet and beautiful spaces to provide opportunities for introspection and reflection. Attendees often need places to calm and remove themselves from the crowds and chaos of festivals anyway. Art instillations are a great way to encourage different levels of thinking and experience. These ideas will not guarantee transformative education, but they give attendees a chance to digest and process their sustainability learning. This will increase the prospect of attendees gaining authentic and valuable sustainability education from the festival's efforts. The sustainability education approaches presented here are specifically applicable to the opportunities associated with music festivals. Investing in attendees with education not only creates a better return on a festival's sustainability initiatives, but it generates a powerful contribution to society and the greater transition of sustainability.

4) Share information about sustainability solutions. The fourth recommended strategy for improved sustainable event management is for event organizers to share 
information about sustainability solutions. The findings revealed that music festival organizers' need a more accurate perception of sustainable event management and an improved understanding of sustainability practices and methods. These needs can be partially addressed with more information circulating through the music festival community about sustainable event management. By sharing successes and failures of the solutions used to address sustainability issues of music festivals, more information will be available to improve methodologies. Moreover, sustainable event management will become common practices more easily if organizers can learn from one another's mistakes and save time and energy not reinventing the wheel. A shift from a competitive to collaborative world view and ways of practice is fundamental to sustainability thought (Sterling, 2001). Cooperating to share successes and failures of sustainability initiatives is the best way to push through the learning curves and road blocks of unfamiliar sustainability methods and practices.

In the current time, there is extremely little information sharing regarding sustainability within the music and entertainment industry in the United States (Wangro, 2010). Limited information sharing stifles the overall development of sustainability within the music festival community. The study results showed that participants rated cooperation as one of the least effective factors in the Likert-scale to help music festival organizers improve sustainable event management. This reveals that event organizers are not engaging, are not convinced of or have not considered the benefits of sharing information of sustainability solutions. However, when information sharing and cooperation was discussed in each of the interviews, the interview participants expressed 
strong interest in cooperation. Information sharing and cooperation are extremely feasible, but are not as pursued or utilized as could be. Information sharing will minimize the challenges associated with the implementation of sustainability practices and methods, reduce misperception surrounding the state of sustainable event management and dispel myths of sustainability solutions being unattainable due to excessive costs.

Information sharing may also stimulate the improvement of a standard sustainability baseline and encourage the development of service providers. Wangro (2010) found that when sustainability information is shared, players within the United States music and entertainment industry become motivated and quickly make changes to their productions. When these changes are made within the industry, new service providers pop up to fulfill the needs of the altered market (Wangro). Therefore, information sharing by music festival organizers of sustainability methods and practices may encourage more activity and development within the marketplace for sustainable event management needs.

Sharing of information between music festivals to stimulate these benefits can only manifest through intentional cooperation and organization between music festival organizers. This thesis recommends that event organizers share their stories, models and case studies of their festivals. Information sharing can be initiated by posting sustainable event management visions, missions, goals, outcomes, and lessons learned on festival websites. Peats Ridge, in Glenworth Valley, Australia, is a great example of a festival working to share its sustainability information. The festival strives to be a resource and 
"model event" to other festivals by sharing its sustainability agenda, stories, resources, and useful links on its website (Peats Ridge, 2010). Other festivals such as Boom and Lightning in a Bottle compile annual sustainability reports to make their information available to the public and other event organizers. Information sharing is not only about providing information about one's own festival, but also seeking out information from other festivals. There is much to be learned from seeking inquiry from other festivals, particularly from international leaders. More widespread information dissemination and detailed discussion of sustainability methodologies can be achieved through the facilitation of organizing body. This option will be further discussed in another recommended strategy.

5) Cooperate to strategically build demand and reduce costs. The fifth recommended strategy for improved sustainable event management of music festivals is also centered on cooperation of event organizers. Cooperation of music festivals can not only be utilized to reap the benefits of information sharing; it can also increase purchasing power to lower costs of sustainability solutions. The costs of sustainability materials, products, services and infrastructure will decrease with increased demand. By aligning and organizing interests, event organizers can build purchasing power to reduce these costs, make sustainability solutions more accessible and address the barrier of costprohibitive solutions. Strategic cooperation of festivals can also be utilized to alleviate the barrier of limited sustainable infrastructure and services. This thesis recommends that music festivals can organize interests for services like composting toilets, mobile solar power or biofuel generators, energy efficient lighting or sound production, organic and 
healthy food vendors, and alternative transportation infrastructure. Infrastructure that supports sustainable event management is needed by event organizers, but won't come into the marketplace until there is sufficient demand. Successful sustainability achievements have stemmed from bodies organizing to create power. If music festivals want more cost-effective services or products, they are going to have to demand them.

Festival organizers of particular music genres and circuits should also strategize to build sustainability learning and investment in the same attendee base. Attendees who are engaged and enthused for sustainably managed music festivals will create demand for sustainable events and thereby reduce costs. With more public support for sustainable events, event organizers are able to make more investment into sustainability initiatives. Cooperation to strategically build demand can also take form between the festival and its host community, local partners and collaborators. For example, if a host community is in need of improved transportation options, event organizers can partner with local parties to advocate for such improvements. The significance of building strategic alliances for sustainable event management amongst sponsors, community groups, venue managers, attendees and other stakeholders has been recognized in the literature (Brooks, O'Halloran \& Magnin, 2007; Getz, 2009; Laing \& Frost, 2009), but hasn't yet come to full fruition on a large scale in the United States music festival community. Cooperation will require careful intention and organization and of music festival organizers.

6) Form an organizing body or alliance. The sixth recommended strategy is the formation of an organizing body or alliance to encourage the adoption and expansion of the sustainable event management of music festivals. One of the purposes of such an 
alliance would be to facilitate the previously discussed strategies of information sharing and cooperation of music festivals organizers. Music festival organizers are very busy and would much benefit from an alliance to assist with the necessary organization, communication, networking and exchanges involved with information sharing and cooperation. Secondly, the alliance would provide guidance and support to music festival organizers by bridging the gap between academic research and popular understanding and developments of sustainable event management in the field. Good solutions to sustainability issues should include sustainability theories, principles of ecology, and understanding of systems (Capra, 2002). While this is prevalent in academia, there is a great of chasm between the academic sphere and that of public life and leadership (Getz, 2009). An alliance will need to be effective at translating these kinds of science-based ideas and technical developments to the field-based music festival community. The third purpose of such an alliance will be to build public consciousness and priority of sustainability awareness. Public consciousness may be the most critical functions of this alliance because attendees are such a central and integral stakeholder to music festivals.

To effectively fulfill these purposes, such an organizing body or alliance will need to have specific qualities that accommodate the characteristics of the music festival sector. The alliance should be inclusive of the great diversity of the music festival community across musical genres, cultures, and regions. Therefore, its membership should be representative of the whole music festival community in all its diversity. The alliance should be advised by a combination of respected leaders in the music industry, event industry, public institutions or organizations, and of leading sustainably managed 
music festivals. A broad balance of innovators from varied arenas will create reputability and encourage buy-in and acceptance from across the music festival community. It is possible that existing organizations in the United States could take on this role, but guidance should be sought from other successful models. A good example of an organizing body that achieved success in these areas is Julie's Bicycle in the United Kingdom. Julie's Bicycle is an organization that provides guidance and training, produces research and practical guides, and launches campaigns and collaborations for the reduction of environmental impact in the music industry (Julie's Bicycle, n.d.). The music festival community in the United States would much benefit from an alliance that plays similar roles. Such an alliance can also work to oversee the development and formation of a sustainability rating and certification system for sustainable music festivals.

7) Create a sustainability rating and certification system. The last strategy recommended in this thesis is for the creation of a voluntary rating system of sustainable practices and indicators to be devised and promoted throughout the music festival community. Simultaneously, the development of a third-party certification system is recommended to facilitate the certifying of music festivals that attain levels of achievement within this rating system. This strategy will serve two purposes. First, the development of a sustainability rating and certification system will significantly improve general understanding of sustainable event management practices and methods and ease the confusion and misperceptions that exist around the topic. Secondly, this strategy will build public consciousness, buy-in and priority of sustainable event management. Serving 
these two purposes, a sustainably rating and certification system will improve the standard baseline for sustainable event management that is accepted of music festivals. This means that stakeholders will come to expect more and better sustainability initiatives of music festivals. Currently, the accepted standard for sustainable event management is a 'clean and green' recycling program (Getz, 2009). Music festivals need to move beyond recycling if they are going to reach their greater potential of being leaders in the sustainability transition. With an improved sustainability standard, stakeholders will begin to expect integrated materials consumption and waste management programs, visible energy conservation efforts, interactive educational opportunities, fair compensation for festival staff, local and organic food, low-impact public transportation options, and a collaborative host community. There are many other sustainability practices that may come to be expected if the baseline standard can be improved.

While the benefits of a sustainability rating and certification system are many, the challenge of this strategy is in developing a system that will become well-accepted as common practice in the music festival sector. Many sustainability rating systems and greening guides have been designed for both music festivals and events in general. In addition, formal standards, including the ISO20121 and BS8901, will likely gain greater prominence in the near future. The goal is not to not reinvent the wheel, but to create something that is needed. Therefore, energy should not be invested into designing a new set of guidelines for the sustainability rating system. Rather, the sustainability rating system should be adopted or compiled from those already in existence. This set of standardized sustainability practices and indicators should be simple and equally include 
environmental, social and economic sustainability practices. Energy should be invested into building consensus and promotion around one so that is well-accepted. The objective is to give event organizers a bit of guidance while building public consciousness and buy-in around sustainable event management. This thesis asserts that a significant part of the purpose of a sustainability rating system and certification is to build public consciousness, demand and priority around sustainable event management. Attendee's participation and investment is especially imperative for music festivals, and building their demand with this certification is critical. The certification needs to understandable and accepted by the public. It also needs to be something that can be trademarked, branded and something the public can embrace. A Greener Festival Award, based in the United Kingdom, is a great example of an event-greening achievement that is well-understood and received within the public eye (A Greener Festival, Ltd., n.d.). It has begun to fill this role in United States music festivals but doesn't have a strong enough reach because it is a moderately selective award rather than a certification. Therefore, a sustainability rating and certifications system that is easily accessible and understandable to music festival stakeholders and the greater public is needed to fill this role.

The establishing process of the sustainability rating and certification system for the music festival sector might be modeled after the Leadership in Energy and Environmental Design (LEED) Green Building Rating System. LEED is a standard developed for design, construction and operation of green buildings that was developed by the United States Green Building Council (USGBC). The widespread use of the 
LEED rating system has transformed the building design and construction industry and become a hallmark demonstrating an open and transparent process where criteria for the rating system is reviewed by over 10,000 USGBC membership organizations (Doak, 2009). LEED is effective because it is a third party consensus-based certification developed by leaders in the field, and because it is accessible, accepted and easily understood by the public. For the sustainability rating and certification of the music festival sector to be successful, it is imperative that the developing body is consensusbased and backed by wide range of respected leaders in the field. Whether it is facilitated by a public agency, private agency, or non-governmental organization, the system should have rules of procedure for both the development of standards as well as a certifying process, developed through a formal voluntary consensus process characterized by openness and due process, and include some degree of transparency and public comment (Atlee \& Roberts, 2008).

In adopting a sustainability rating and certification system, it is critical that the diversity and variability of the music festival community is acknowledged. Each music festival has a unique variable set that is determined by its culture, access to infrastructure, government support, funding options, partners, scale and other variables. This means that each music festival has a unique fingerprint that will require unique sustainability solutions. It is important to acknowledge prescriptive rules and methods for implementing sustainability practices and processes is not the best approach for music festivals. Unlike the LEED certification that standardizes the construction of permanent buildings, music festivals have a very dynamic nature and are phenomenological, 
impermanent creations. It is important to remember that the most appropriate sustainability solution will always be relative to the particular context and variables of the immediate time and space. Therefore, the sustainability rating and certification system for sustainable event management should be crafted in a way that respects this dynamic and variable nature of music festivals. The rating system should be simple, accessible, and respect and encourage festival creativity. It should include basic sustainability practices but should avoid top-down command and control standardization. The sustainability rating system should encourage organizers to adopt pragmatic, place and culturally based solutions customized to each festival's unique variable set. The rating and certification system will bring great benefits to the improvement of sustainable event management, but can only be developed once a strong organizing body or alliance is fully functioning.

Some of these seven recommended strategies can be adopted by event organizers independently, while others require cooperation and collaboration. They each require hard work, the willingness to make changes and the acceptance of different views and ways of doing things. Unfortunately there is not magic solution or silver bullet that will make sustainable event management of music festivals easy or immediate. It is important to remember that sustainability is a process, and good solutions are often slow. These recommended strategies will take time, but will support the emergence of improved sustainable event management. 


\section{Implications}

The findings of this study fill an important gap in the academic literature on events and sustainability. Currently there is little research that converge events with sustainability. The findings of this study align with those from the few existing pieces of research on sustainable event management. This study supports the recommendations of the Brooks, O’Halloran \& Magnin (2007) study of strategic planning of music festivals through a sustainability framework, and similarly provides a sustainability theory and systems approach to the field of event management. This study expands on the Brooks et al. study by providing incremental steps of organizational change in the direction of sustainability framing. In contrast to the Brooks et al. study, this thesis stresses the importance of a holistic scope in sustainable event management by addressing environmental, social and economic dimensions equally. Additionally, this study aims to fill the gap between academic research and implementation in the field by specifically targeting the challenges and needs that music festival organizers encounter in their work. The recommended strategies of this thesis are valuable because they combine the findings of this study with existing strategies of sustainable events and lessons drawn from organizational change studies.

This study is immediately applicable to United States music festivals. The findings were drawn directly from event organizers' challenges and successes with sustainable event management, and the strategies were designed to be specifically applied to their work. The findings showed that sustainability is extremely important to music festivals. The United States music festival community is heading in the direction of 
sustainability, and this study's results and recommendations provide strategies that will make sustainable event management more readily adopted and improved. Music festival organizers are actively seeking reasons to invest in a sustainable direction that won't eat into their bottom line nor jeopardize their festival viability. The strategies recommended by this thesis provide a holistic approach to sustainable event management that will collectively addresses festival sustainability as a whole.

\section{Where to Go From Here}

This thesis calls for music festival organizers to take action as sustainability leaders and innovators not only in sustainable event management, but in the greater sustainability transition. Getz (2009) asserts the need for non-academic champions to take leadership and push the sustainability paradigm into public consciousness. Music festivals are already perfectly aligned to embrace this leadership role and work to inspire sustainability education and activation to the millions of music festival attendees that participate in music festivals annually. Now is the time for organizers to cooperate, share ideas, unleash their creative prowess and take bold moves to be leaders. European and Australian festivals are already leading the way. It is time for United States music festival organizers to find the fires in their bellies, charge through perceived limitations and let loose their expression and innovation.

It is time to start recognizing music festivals for their great value and potential to contribute to the sustainability transition. It is imperative that music festival organizers learn to recognize and assert the value of their festivals or risk losing them. Valuation of music festivals should be further explored and studied. If the tangible and intangible 
values of music festivals can be better understood and valuation techniques and measurement systems more accessible, music festivals will become better valued by society and in economy.

\section{Concluding Thoughts}

The challenges of the $21^{\text {st }}$ century are time-sensitive, and activating the transition of sustainability is urgent. This is a time for envisioning, innovation and investing in creative and bold ideas. Music festivals are unique phenomenon that helps people rejuvenate their needs for belonging, consciousness and humanity. When the negative impacts of music festivals are mitigated and their positive impacts cultivated, they can be valuable contributions to betterment. If sustainable event management can become common practice, music festivals will have unlimited potential to educate and empower the capabilities of people to contribute to sustainability. Sustainably managed music festivals can be models of collaborative partnerships and living laboratories for new ideas, technologies and ways of living.

The researcher's understanding of sustainability changed substantially through the course of this study. Through data collection, interactions with the study participants, reviews of literature, explorations of public perception and digestion of all the research to create recommended strategies, the researcher's relationship with sustainability developed immensely. The researcher now realizes that sustainability is not simply a set of initiatives that can be implemented into any one organization or program. Rather sustainability is a concept that already exists in the present. Sustainability merely means sustaining all the wonderful aspects of life that contribute to a healthy and desirable 
world and working to phase out those parts that are detrimental. This seemingly minute change in understanding gives way to entirely different approach to sustainability in practice.

This approach to sustainability means that all music festivals are a part of sustainable event management. The clear and simple fact is that United States music festivals need to be sustained. Therefore, it is imperative that sustainable event management becomes common practice. Event organizers need to sustain their attendee bases, stakeholders, community networks and relationships, and host communities so that music festivals can also be sustained. Event organizers also need to sustain the natural environment and keep the planet healthy and regenerative so that music festivals can be viable investments in the new economy. So let music festivals be sustained so they can be valuable contributions to society and guide communities in the transition to a more sustainable future. 


\section{References}

A Greener Festival, Ltd. (n.d.). www.agreenerfestival.com. Retrieved from http://www.agreenerfestival.com/

Anderson, T., \& Getz, D. (2008). Stakeholder management strategies of festivals. Journal of Convention and Event Tourism, 9(3), 199-220.

doi:10.1080/15470140802323801

Atlee, J., \& Roberts, T. (2008, January). Behind the logos: Understanding green product certifications. Environmental Building News, 17(1). Retrieved from http://www.buildinggreen.com/auth/article.cfm/2008/1/1/Behind-the-LogosUnderstanding-Green-Product-Certifications/

Arcodia, C., \& Whitford, M. (2006). Festival attendance and the development of social capital. Journal of Convention and Event Tourism, 8(2), 1-18. doi:10.1300/J452v08n02_01

Ayers, R. (1989). Industrial metabolism and global change. International Social Sciences Journal, 12, 23-42.

Baumgartner, L. M. (2001). An update on transformational learning. New Directions for Adult and Continuing Education, 89, 15-24.

Berkes, F., \& Folke, C. (Eds.). (1998). Linking social and ecological systems:

Management practices and social mechanisms for building resilience. Cambridge, UK: The Press Syndicate of The University of Cambridge.

Berry, W. (2005). Solving for patterns. In M.K. Stone \& Z. Barlow (Eds.), Ecological literacy: Educating our children for a sustainable world (pp. 85-95). San Francisco, CA: Sierra Club Books.

Bolman, L. G., \& Deal, T. E. (2008). Reframing organizations: Artistry, choice and leadership (4th Ed.). San Francisco, CA: Jossey-Bass.

Brooks, S., O’Halloran, D., \& Magnin, A. (2007). Rock on!: Bringing strategic sustainable development to music festivals. (Unpublished master's thesis) Blekinge Institute of Technology, Karlskrona, Sweden.

Braungart, M., McDonough, W., \& Bollinger, A. (2007). Cradle-to-cradle design: Creating healthy emissions - a strategy for eco-effective product and system design. Journal of Cleaner Production, 15 (pp. 13-14), 1337-1348.

doi:10.1016/j.jclepro.2006.08.003 
Burgman, B., \& Mules, T. (2000). Estimating the impact of events - Sampling frame issues in identifying event related expenditure. In J. Allen, R. Harris, L. Jago, \& A. J. Veal (Eds.), Beyond 2000: Setting the agenda - event evaluation and research (pp. 52-74). Sydney: Australian Centre for Event Management.

British Standards Institute. (2010). BS 8901 Sustainability Management Systems for Events. Retrieved from http://www.bsigroup.co.uk/en/Assessment-andCertification-services/Management-systems/Standards-and-Schemes/BS-8901/

Capra, F. (2002). The hidden connections: A science for sustainable living. New York, NY: Anchor Books.

Capra, F. (2005). Preface: How nature sustains the web of life. In M.K. Stone \& Z. Barlow (Eds.), Ecological literacy: Educating our children for a sustainable world (pp. 85-95). San Francisco, CA: Sierra Club Books.

Clark, M. C. (1993). Transformational learning. In S. B. Merriam (Ed.), An update on adult learning theory: New directions for adult and continuing education, 57. San Francisco, CA: Jossey-Bass.

Convention Industry Council. (2010). APEX/ASTM Environmentally Sustainable Meeting Standards. Retrieved from: http://www.conventionindustry.org/StandardsPractices/GreenMeetings/APEXAS TM.aspx

Cranton, P. (2002). Teaching for transformation. New directions for adult and continuing education, 93, 63-71.

Daly, H.E. (1993). Sustainable growth: An impossibility theorem. In H. E., Daly \& K. N. Townsend (Eds.), Valuing the earth: Eco-nomics, ecology, ethics (pp. 267-274). Cambridge, MA: MIT Press.

Daly, H.E. (1996). Beyond Growth. Washington, DC: Beacon Press.

David, L. (2009). Environmental impacts of events. In R. Raj \& J. Musgrave (Eds.), Event management and sustainability (pp. 66-75). London, UK: CAB International.

Doak, J. (2009, October). A certifications guide. Display and design ideas, 21(10), 16.

Dwyer, L., Mellor, R., Mistilis, N., \& Mules, T. (2000). A framework for evaluating and forecasting the impacts of special events. In J. Allen, R. Harris, L. Jago, \& A. J. Veal (Eds.), Beyond 2000: Setting the agenda - event evaluation and research (31-39). Sydney: Australian Centre for Event Management. 
Dwyer, L., Forsyth, P., \& Spurr, R. (2005). Estimating the impacts of special events on the economy. Journal of Travel Research, 43, 351-359. doi: $10.1177 / 0047287505274648$

Dyllick, T., \& Hockerts, K. (2002). Beyond the business case for sustainability. Business Strategy and the Environment, 11, 130-141. doi:10.1002/bse.323

Easterbrook, G. (2003). The progress paradox: How life gets better when people feel worse. New York, NY: Random House.

Edwards, A. E. (2005). The sustainability revolution: Portrait of a paradigm shift. Gabriola Island, Canada: New Society Publishers.

Elkington, J. (1998). Cannibals with forks: The triple bottom line of the $2 I^{\text {st }}$ century business. Oxford, UK: Capstone Publishing Limited.

Evans, T. L. (2010). Critical social theory and sustainability education at the college level: Why it's critical to be critical. Journal of Sustainability Education, 1, Retrieved from http://journalofsustianabilityeducation.org/

Festival Media Corporation (n.d.). Festivals.com. Retrieved from http://www.festivals.com/

Festival Media Corporation (n.d.). Festival Finder. Retrieved from: http://www.festivalfinder.com/

Foley, M., \& McPherson, G. (2007). Glasgow's winter festival: Can cultural leadership serve the common good? Managing Leisure, 12, 143-156. doi:10.1080/13606710701339330

Fraser, S. (April 22, 2008). The great silence: Our gilded age and theirs. TomDispatch. Retrieved from http://www.tomdispatch.com/post/174922

Gay, L. R., Mills, G. E., \& Airasian, P. (2009). Educational research: Competencies for analysis and applications. Upper Saddle River, NJ: Pearson.

Georg, S. \& Fussel, L. (2000). Making sense of greening and organizational change. Business and the Environemnt, 9, 175-185.

Getz, D. (2009). Policy for sustainable and responsible festivals and events: Institutionalization of a new paradigm. Journal of Policy Research in Tourism, Leisure and Events, 1(1), 61-78. doi:10.1080/19407960802703524 
Goodwin, N. R. (2003). Five kinds of capital: Useful concepts for sustainable development. Global Development and Environment Institute Working Paper No. 03-07. Tufts University, Medford, MA.

Greenhaus, M. (2010, June). $10^{\text {th }}$ Annual festival guide. Relix Magazine, 37(3), 58-67.

Grey, R., Walters, D., Bebbington, J., \& Thompson, I. (1995). The greening of enterprise: An exploration of the (non) role of environmental accounting and environmental accountants in organizational change. Critical Perspectives on Accounting, 6 , 211-239.

Gruenewald, D. A. (2003). Foundations of place: A multidisciplinary framework for place-conscious education. American Educational Research Journal, 40(3), 619654. doi:10.3102/00028312040003619

Hancock, D. R., \& Algozzine, B. (2006). Doing case study research: A practical guide for beginning researchers. New York, NY: Teachers College Press.

Harris, L. C., \& Crane, A. (2002). The greening of organizational culture: Management views on the depth, degree and diffusion of change. Journal of Organizational Change Management, 15(2), 214-234. doi:10.1108/09534810210429273

Higgins, P. (2009). Into the big wide world: Sustainable experiential education for the $21^{\text {st }}$ century. Journal of Experiential Education, 32(1), 44-60.

Hodur, N., \& Leistritz, F. (2006). Estimating the economic impact of event tourism: A review of issues and methods. Journal of Convention and Event Tourism, 8(4), 63-79. doi:10.1300/J452v08n04_05

Hollings, C. S. (2001). Understanding the complexity of economic, ecological, \& social systems. Ecosystems, 4, 390-405. doi:101007/s10021-001-0101-5

Holt, F. (2010). The economy of live music in the digital age. European Journal of Cultural Studies, 13(2), 243-261. doi:10.1177/1367549409352277

International Organization for Standardization. (2011). ISO to develop sustainable event standard in run-up to 2012 Olympics. Retrieved from http://www.iso.org/iso/pressrelease.htm?refid=Ref1281

Jabbour, C. J. C., \& Fernando, C. A. S. (2008). The central role of human resources management in the search for sustainable organizations. The International Journal of Human Resource Management, 19(12), 2133-2154. doi:10.180/09585190802479389 
Jackson, J., Houghton, M., Russell, R., \& Triandos, P. (2005). Innovations in measuring economic impacts of regional festivals: A do-it-yourself kit. Journal of Travel Research, 43, 360-367. doi:10.1177/004728750527449

Jackson, T. (2009, March 30) Prosperity without growth? - The transition to a sustainable economy. United Kingdom: Sustainable Development Commission. Retrieved from http://www.sd-commission.org.uk/data/files/publications/prosperity_without growth_report.pdf

JamBase Inc. (n.d.). Music festival guide, festival ticket listing. Retrieved from http://www.jambase.com/Festivals/

Jones, M. (2010). Sustainable event management: A practical guide. London, UK: Earthscan.

Jones, M., \& Scanlon, X. (2010, March). Singing to a greener tune: Current status of the music industry in addressing environmental sustainability. Retrieved from http://www.grida.no/files/workshops/music-environment/ Singing\%20to\%20a\%20Greener\%20Tune\%20DRAFT\%20REPORT.pdf

Julie’s Bicycle (2008). Julie's Bicycle. Retrieved from: http://www.juliesbicycle.com/

Katzel, C. T. (2007). Event greening: Is this concept providing a serious platform for sustainability best practice? (Unpublished master's thesis). University of Stellenbosch, Stellenbosch, South Africa.

Karlsen, S., \& Brandstrom , S. (2008). Exploring the music festival as a music education project. International Journal of Music Education, 26, 363. doi:10.1177/0255761408096077

Kotter, J. P., \& Cohen, D. S. (2002). The heart of change: Real life stories of how people change their organizations. Boston, MA: Harvard Business School Press.

Laing, J., \& Frost, W. (2010). How green was my festival: Exploring challenges and opportunities associated with staging green events. International Journal of Hospitality Management, 29, 261-267. doi.org/10.1016/j.ijhm.2009.10.009

Latham, A. (Ed.). (2002) The Oxford Companion to Music. New York, NY: Oxford University Press Inc.

Lubin, D. A., \& Esty, D. C. (2010, May). The sustainability imperative: Lessons for leaders from previous game-changing megatrends. Harvard Business Review, 4250 . 
Meadows, D. H. (2008). Thinking in systems: A primer. D. Wright, (Ed.). White River Junction, VT: Chelsea Green Publishing.

Meadows, D., Randers, J., \& Meadows, D. (2002). A synopsis: Limits to growth: The 30 year update. White River Junction: Chelsea Green.

McKewon, R. (2002). Education for sustainable development toolkit. Version 2.

Retrieved from http://esdtoolkit.org

MetroWize (n.d.). The urban aficonado's guide to music, food, nightlife and culture in your city. Retrieved from http://www.metrowize.com

Mitchell, M., Curtis, A., \& Davidson, P. (2008). Evaluating the process of triple bottom line reporting: Increasing the potential for change. Local Environment, 13(2), 6780. doi:10.1080/13549830701581937

Millenium Ecosystem Assessment. (2005). Ecosystems and human well-being: General synthesis. Retrieved from:

http://www.maweb.org/documents/document.356.aspx.pdf

Orr, D. (2004). Earth in mind: On education, environment and the human prospect. Washington DC: Island Press.

Peats Ridge. (2010). Sustainability - What does it mean and why do we do it? Retrieved from http://www.peatsridgefestival.com.au/sustainability

Pfeffer, J. (2010). Building sustainable organizations: The human factor. Academy of Management Perspectives. 34-45.

Polese, M., \& Stren, R. (Eds.). (2000). The social sustainability of cities: Diversity and the management of change. Toronto: University of Toronto Press.

Rabin, C. P., \& Elke, C. (1990). Music festivals in America: classical, opera, jazz, pops, country, old-time fiddlers, folk, bluegrass, Cajun. Great Barrington: Berkshire Traveler Press.

Raj, R., \& Musgrave, J. (2009). The economics of sustainable events. In R. Raj \& J. Musgrave (Eds.), Event management and sustainability. London, UK: CAP International.

Reily, A. H. (2009). Communicating sustainability initiatives in corporate reports: Linking implications to organizational change. S.A.M. Advanced Management Journal, 74(3), 33-43. 
Remington, S. (2003). The power of festivals to build community. International Events Magazine 14(2).

Rifkin, J. (2009). The empathetic civilization: The race to global consciousness in a world in crisis. New York, NY: Penguin.

Robertson, M., Rogers, P., \& Leask, A. (2009). Progressing socio-cultural impact evaluation for festivals. Journal of Policy Research in Tourism, Leisure and Event. 1(2), 156-169. doi:10.1080/19407960902992233

Saayman, M., \& Rossouw, R. (2010). The Cape Town international jazz festival: More than just jazz. Development Southern Africa, 27(2), 255-272. doi:10.1080/03768351003740696

Sadie, S., \& Tyrrell, J. (Eds.). (2001). The New Grove Dictionary of Music and Musicians (Egypt to Flor) $\left(2^{\text {nd }}\right.$ ed.). Volume 8. London, UK: Macmillan Publishers Limited

Sen, A. (2010). Music in the digital age: Musicians and fans around the world "come together" on the net. Global Media Journal, 9(16), 1-25.

Senge, P. (1990). The fifth discipline. New York, NY: Doubleday.

Senge, P. (2008 July/August). As the bubble pops. The Conference Board Review, 3339. Retrieved from http://www.conferenceboard.org/articles/atb_article.cfm?id=479\&pg=2

Shahjahan, R. A., (2004). Centering spirituality in the Academy: Toward a transformative way of teaching and learning. Journal of Transformative Education, 2(4). doi:10.1177/1541344604268330

Sharp, L. (2002). Green campuses: the road from little victories to systemic transformation. International Journal of Sustainability in Higher Education,3(2), 128-145. doi:10.1108/14676370210422357

Sharpe, E. (2008). Festivals and social change: Intersections of pleasure and politics at a community music festival. Leisure Sciences, 30, 217-234. doi:10.1080/01490400802017324

Smith, A. (2009). Theorizing the relationship between major sporting events and social sustainability. Journal of Sport and Tourism, 14(2-3), 109-120. doi:10.1080/14775080902965033 
Sterling, S. (2001). Sustainable education: Re-visioning learning and change. Devon, UK: Green Books.

Sustainable Event Alliance. (2011). Sustainable Event Alliance. Retrieved from http://www.sustainable-event-alliance.com/?page_id=27

The Do Lab. (2010). Lighting in a bottle: 2010 Greening report. Retrieved from http://lightninginabottle.org/wp-content/uploads/ 2011/04/GreenReport2010_ small.pdf

The Oxford American College Dictionary (2002). New York, NY: Oxford University Press.

The Natural Step. (2009). United States sustainability primer: Step by natural step. Portland, OR. Retrieved from http://www.naturalstep.org/en/canada/primerresources

United Nations Environment Programme. (n.d.). Music and Environment Initiative. Retrieved from http://www.unep.org/music_env/about.asp

United Nations Environment Programme. (2009). Green meeting guide 2009: Roll out the carpets for your participants. Retrieved from http://www.unep.fr/scp/sun

Wangro, C. (2010). United nations music and environment stakeholder meeting. [presentation at the UN M\&E workshop] Retrieved from http://www.grida.no/files/workshops/musicenvironment/Chris\%20Wangro\%20Presentation.pdf

Wikipedia (n.d.). List of festivals in the united states: Music festivals. Retrieved from http://en.wikipedia.org/wiki/List_of_festivals_in_the_United_States\#Music_festiv als

Wood, E. (2005). Measuring the economic and social impacts of local authority events. International Journal of Public Sector Management, 18(1), 37-53. doi:10.1108/09513550510576143

World Commission on Environment and Development. (1987). Our common future. Oxford, UK: Oxford University Press.

Young, W., \& Tilley, F. (2006). Can businesses move beyond efficiency? The shift toward effectiveness and equity in the corporate sustainability debate. Business Strategy and the Environment, 15, 402-415. doi:10.1002/bse.510 
Yourope. (n.d.). Yourope: The European festival association. Retrieved from http://www.yourope.org/index.aspx 


\section{Appendix A: Sustainable Event Management Survey for Event Organizers}

Thank you for agreeing to take this survey! Your participation is greatly appreciated.

For this survey, SUSTAINABLE EVENT MANAGEMENT is defined as the inclusion of sustainability policies, processes and practices into event management. The goal is to minimize the negative impacts of events while encouraging the positive ones.

SUSTAINABILITY is defined within the domains of economy, society and environment as is consistent with the triple bottom line. The TRIPLE BOTTOM LINE is a framework for measuring and reporting organizational performance equally against these three parameters.

1) I agree to take this survey. I have read the above cover letter of informed consent, and I understand that all my answers are completely confidential. (Y/N)

\section{First, please tell us a bit about your festival!}

2) How many patrons attended your festival last year?
a. Less than 5,000
b. Up to 10,000
c. Up to 20,000
d. Up to 40,000
e. Up to 80,000
f. Up to 100,000
g. More than 160,000

3) What genre of music best descrihes vour festival?
a. Bluegrass
i. Jammy
b. Blues
j. Jazz
c. Country
k. Mixed genre
d. Classical
1. Other
e. Dance
m. Popular
f. Electronic
n. Reggae
g. Folk
o. Rock
h. Indie
p. World

4) How is your festival produced?
a. Production company/corporation
b. Independent entity/ individual(s)
c. Public entity
d. Non-profit organization
e. Collaboration amongst the above
f. Other 
SUSTAINABLE EVENT MANAGEMENT

Next, please rate your music festival's engagement with triple bottom line sustainability under the following conditions. For each question below, one ranks low and ten ranks high.

5) How important are sustainability concepts, practices and processes to your festival?

$\begin{array}{lllllllllll}< & 1 & 2 & 3 & 4 & 5 & 6 & 7 & 8 & 9 & 10\end{array}$

6) Economic sustainable event management initiatives might include local business partnerships, place marketing of host city, demonstrable 'legacy' contributions to host city, leveraging the event for generic economic development, etc. Please rate your festival's ECONOMIC initiatives last year:

$\begin{array}{lllllllllll}< & 1 & 2 & 3 & 4 & 5 & 6 & 7 & 8 & 9 & 10\end{array}$

7) Social sustainable event management initiatives might include local arts and cultural development, health and wellness enhancement, stakeholder consensus building, mandatory living wages, etc. Please rate your festival's SOCIAL initiatives last year:

$\begin{array}{llllllllllll}< & 1 & 2 & 3 & 4 & 5 & 6 & 7 & 8 & 9 & 10\end{array}$

8) Environmental sustainable event management initiatives might include waste recovery and minimization, renewable energy usage, greenhouse gas inventories, resource lifecycle accounting, efficient transport systems, etc. Please rate your festival's ENVIRONMENTAL initiatives last year:

$\begin{array}{llllllllllll}< & 1 & 2 & 3 & 4 & 5 & 6 & 7 & 8 & 9 & 10\end{array}$




\section{Please tell us a bit about yourself.}

9) This research is surveying only event organizers who are responsible for sustainability related activities and decision making of music festivals. This might include event organizers, operations managers, sustainability coordinators, planners, etc. In your own words, briefly define your title and/or role: (open-ended question)

10) How many years of experience do you have in the event industry?
a. Less than one year
b. 1 year or more, but less than 3 years
c. 3 years or more, but less than 5 years
d. 5 years or more, but less than 10 years
e. 10 years or more

11) How many years of experience do you have working in sustainability? Please count experience where sustainability represented $25 \%$ or more of your responsibilities or frame of mind.
a. I don't consider myself to be working in sustainability
b. Less than one year
c. 1 year or more, but less than 3 years
d. 3 years or more, but less than 5 years
e. 5 years or more, but less than 10 years
f. 10 years or more

12) How much education or training do you have in sustainability? Please check all that apply.
a. Not much
b. I have read books, journals, or publications
c. I have completed a workshop or class
d. I am part of a sustainability-related organization or professional association
e. I have gained on the job or professional experience
f. I have a higher education degree in a sustainability-related field
g. Other, please specify (comments space) 
This next set of questions asks you to rank various factors as to how effective they are in helping you improve the triple bottom line sustainability of your festival. All factors are important, but the aim of these questions is to identify what specifically will most help you in your work. Please be critical when answering these questions and provide comments to clarify your ideas.

\begin{tabular}{|c|c|c|c|c|c|c|}
\hline Factors & 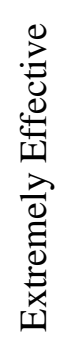 & 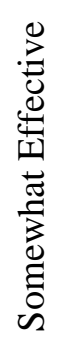 & 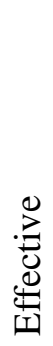 & $\begin{array}{l}\bar{\pi} \\
\text { : } \\
\overline{0}\end{array}$ & 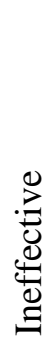 & $\begin{array}{l}\mathscr{\Xi} \\
\tilde{\Xi} \\
\tilde{\Xi} \\
0\end{array}$ \\
\hline $\begin{array}{l}\text { 13) More defined sustainability mission statement and } \\
\text { policies }\end{array}$ & 5 & 4 & 3 & 2 & 1 & \\
\hline 14) Short and/or long term sustainability goals & 5 & 4 & 3 & 2 & 1 & \\
\hline $\begin{array}{l}\text { 15) Better access to quality sustainability standards for } \\
\text { music festivals }\end{array}$ & 5 & 4 & 3 & 2 & 1 & \\
\hline 16) Better access to investment or funding & 5 & 4 & 3 & 2 & 1 & \\
\hline $\begin{array}{l}\text { 17) Improved understanding of the concept and meaning } \\
\text { of the term "sustainability" }\end{array}$ & 5 & 4 & 3 & 2 & 1 & \\
\hline 18) Stronger staff or person-power & 5 & 4 & 3 & 2 & 1 & \\
\hline $\begin{array}{l}\text { 19) Improved understanding of the processes and } \\
\text { practices involved with implementing sustainability }\end{array}$ & 5 & 4 & 3 & 2 & 1 & \\
\hline 20) More cooperation with other music festivals & 5 & 4 & 3 & 2 & 1 & \\
\hline $\begin{array}{l}\text { 21) Improved support from top management or decision } \\
\text { makers }\end{array}$ & 5 & 4 & 3 & 2 & 1 & \\
\hline 22) Different organizational structure of festival & 5 & 4 & 3 & 2 & 1 & \\
\hline $\begin{array}{l}\text { 23) Better consensus of key stakeholders (i.e. owners, } \\
\text { community, partners, artists) }\end{array}$ & 5 & 4 & 3 & 2 & 1 & \\
\hline 24) Better development of the business case & 5 & 4 & 3 & 2 & 1 & \\
\hline $\begin{array}{l}\text { 25) Better internal understanding and cooperation } \\
\text { amongst the festival organization }\end{array}$ & 5 & 4 & 3 & 2 & 1 & \\
\hline 26) Better sustainability measuring / reporting systems & 5 & 4 & 3 & 2 & 1 & \\
\hline
\end{tabular}

(Comments space) 
The last set of questions draws on your experiences and perspectives as an event and / or sustainability professional.

27) What are the greatest challenges you have encountered? (open-ended question, 3 spaces)

28) In your own words, what will most help you improve the triple bottom line sustainability of your festival? (open-ended question

29) What changes or factors do you think could encourage common practice of sustainable event management throughout the music festival community?

(open-ended question)

30) In your opinion, what is the current state of triple bottom line sustainability throughout the music festival community? In this scale 1 is very poor and 10 is excellent.
$<\quad 1$
23
4
56
$7 \quad 8$
$10>$ 
Appendix B:

Interview Questions

1) What does triple bottom line sustainable event management mean to you and your festival?

2) Please expand on the challenges you have faced moving your festival toward sustainability?

3) Despite these challenges, what factors or tools have really helped you to reach your achievements?

4) How do you think your experiences with sustainable event management compare to those of event coordinators within the greater festival community? Please explain.

5) The survey participants rated the current state of sustainability of the United States music festival community a " 5 " out of " 10 ." What are your thoughts on this rating?

6) The survey results showed low interest from event coordinators in standardization of practices and cooperation with other festivals. What role do you think diversity plays in finding sustainable event management strategies for the United States music festival community?

7) The survey participants rated funding issues and economic viability as primary barriers to sustainable event management. What are your thoughts on sustainability just being too cost-prohibitive to work toward for music festivals?

8) Where does your festival look for information, models or leadership in sustainable event management?

9) Is there anything else you would like to add that concerns sustainable event management strategies of music festivals in the United States? 